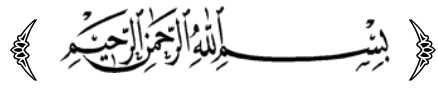

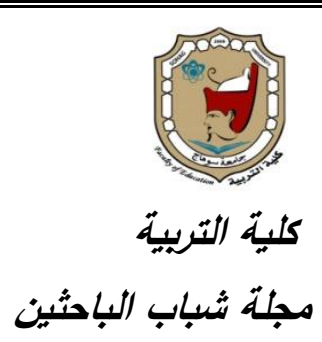

واقع برامجه تربية وتمبيم ذوي الامتياجات الغاصة في هصر

$$
\text { ( بحث مشتق من مسالةعلمية خشصص أصول التبية ) }
$$

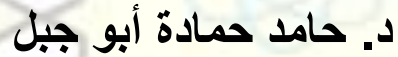

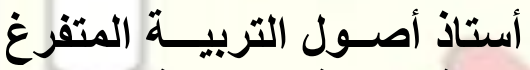

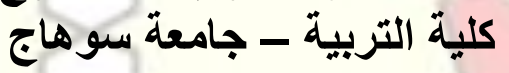

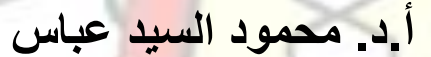
أستاذ أصول التربية وعميد الكلية كلية التربية - جامعة سوهاج

$$
\text { بأحث دكت أبواة عقرب إبراهيم عبد العال }
$$

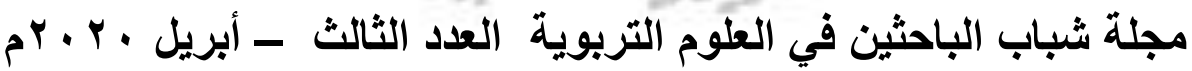
Print:(ISSN 2682-2989) Online:(ISSN 2682-2997) 
ملخص:

تهتم الاولة بملف الإعاقة والأثخاص ذوى الاحتياجات الخاصة، وتعمل على تقديم الرعاية

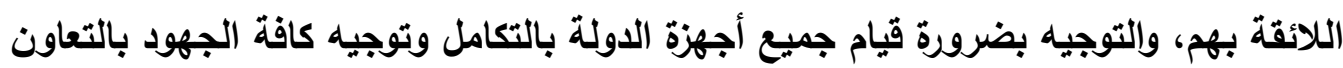

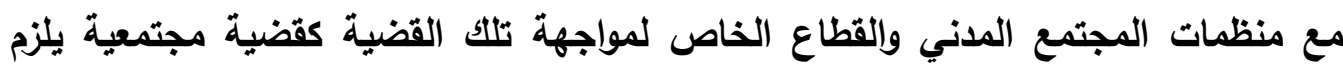
مواجهتها ، وكذلك بالتعاون مع الأثخاص ذوى الإعاقة أنفسهر. كما أن مدارس التربية

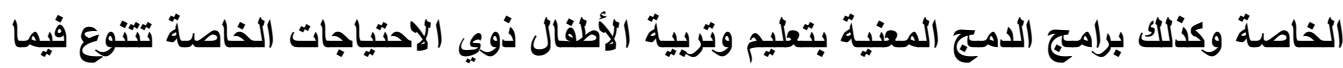
بينها بين مدارس بها إقامة كاملة من مبيت ومعيشة، وبين فصول ملحقة بالمدارس العادية انطلاقاً من مبدأ المساواة كحق أصيل. وهناك النظم الهيكلية والتعليمية لمؤسسات التربية الخاصة بذوي الاحتياجات الخاصة بإعاقاتهم الثلاث؛ سواء الإعاقة البصرية ومدارسها "مدارس النور" أو الإعاقة السمعية

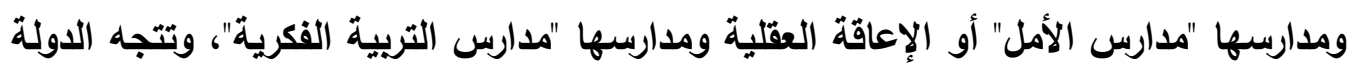
نحو مد مظلة التربية الخاصة نحو دمج ذوي الاحتياجات الخاصة مع العاديين بمدارس التعليم العام، ولكن يؤخذ على شروط القبول بمدارس وفصول التربية الخاصة عدم إمكانية قبول تعدد العوق أو الطالب الذي يحمل أكثر من إعاقة، مما يهلر حقهم في التعليم والرعاية. وهدفت الدراسة الحالية دفع المسئولين بالتربية الخاصة بالاولة للاهتمام بذوي الاحتياجات الخاصة مثل بقية الأطفال العاديين في المجتمع، من خلال تطوير تعليمهم بمدارس التربية

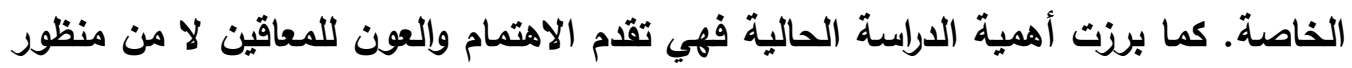
إنساني فحسب بل من منظور اجتماعي وإتصادي وتريوي أيضاً. وإتخدم الباحث في هذه الاراسة المنهج الوصفي من أجل جمع وتحليل المعلومات حول موضوع الدراسة. وفي نهاية هذه الدراسة قدم الباحث روئية لتربية ذوي الاحتياجات الخاصة، وذلك من خلال تبني مشروع شامل لتطوير برامج تربية ذوي الاحتياجات الخاصة مع توفير أليات التنفيذ.

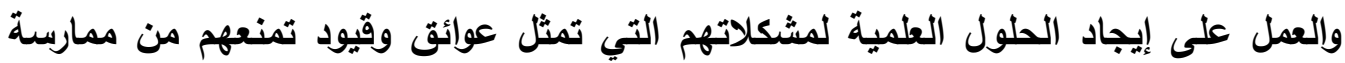
الحياة المنتجة في مجتمعاتهم، لذلك فمن المهم بل الأكثر أهمية أن يُعاد النظر في عملية تربية ذوي الاحتياجات الخاصة، حتي يحقق تعليم ذوي الاحتياجات الخاصة في مصر أهدافه،

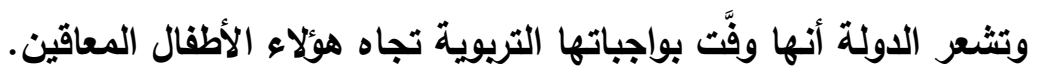




$$
\text { الإطار التمهـيدي للار اسلة الأول }
$$

كل الأديان السماوية حتى الوضعية منها، كفلت مبأ المساواة بين البشر، والمساواة تعني أن يكون الناس متساوين في الحقوق والواجبات، لذلك فمن حق الأطفال من ذوي

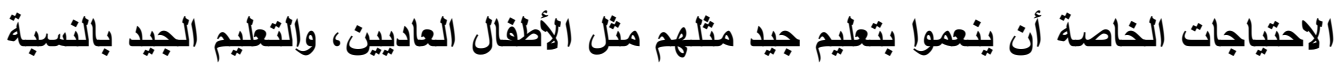
للأطفال ذوي الاحتياجات الخاصة لا يمكن أن يكون واقعياً بدون تخطيط جيد للمدارس بهون والمؤسسات التي ترعاهم تربيةً وتعليماً. ولقد وُجدَ ذوي الاحتياجات الخاصة في كل العصور، وإن اختلفت النظرة من عصر لآخر

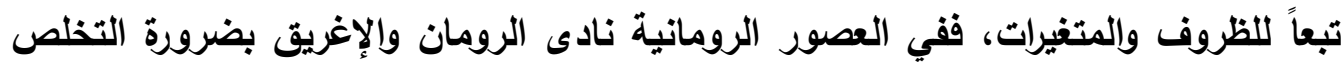
من ذوي الاحتياجات الخاصة لكونهم عالة على المجتمع، فقد ذكر أرسطو صاحب المدينة الفاضلة "أن الطقل الأصم الأبكم غير مُجدٍ تعليمه" وذلك لعدم قدرته على الكلام، كما نادى أفلاطون صاحب الجمهورية بضرورة إقامة مجتمع خالي من العجزة والمشوهين، أما في روما فكانوا يغرقون العميان في نهر"التيبر" لاعتقادهم أن المعاق يحمل في جنباته شيطان أو روحاً

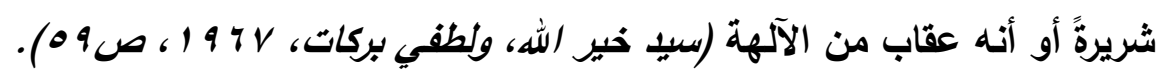

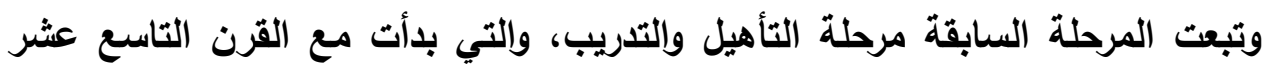

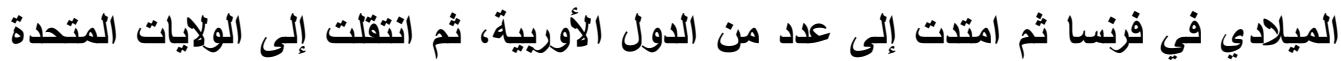
الأمريكية (Jean, G.). ثم مر ذوي الاحتياجات الخاصة بمرحلة الامج)، وتتميز هذه المرحلة بتفهم وتقبل أكثر لذوي الاحتياجات الخاصة فلم تعد الإعاقة مشكلة لاى الفرد المعاق وإنما هي نتيجة لعلاقة تبادلية يمكن نجاحها بين الفرد وبيئته المنظمة لتأهيله للانخراط في المجتمع (Weintraub, F.2005.p98). ومن خلال هذا القانون تم الاهتمام بتعليم الأطفال المعاقين في فصول التعليم العام بناءً على أنهم جزء من مجتمعهم وعليهم أن يتفاعلوا معه وعليه أن يتقبلهم (Florence, J , 2005, p176. كما أن موضوع ذوي الاحتياجات الخاصة من الموضوعات التي شغلت اهتمام علماء النفس والاجتماع والتربية حيث لا يكاد يخلو مجتمع من المجتمعات مهما بلغت درجة تحضره

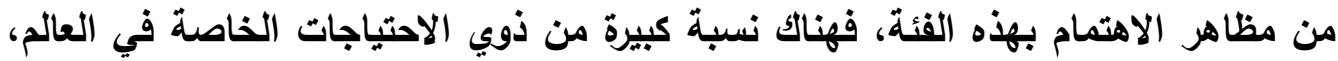
لذلك بدأت العديد من دول العالم الاهتمام بفئة ذوي الاحتياجات الخاصة والعمل على إيجاد 
الحلول العلمية لمشكلاتهم التي تمثل عوائق وقيود تمنعهم من ممارسة الحياة المنتجة في مجتمعاتهم، لذلك فلابد أن يُعاد النظر في منظومة تربية وتعليم ذوي الاحتياجات الخاصة حتي مهي

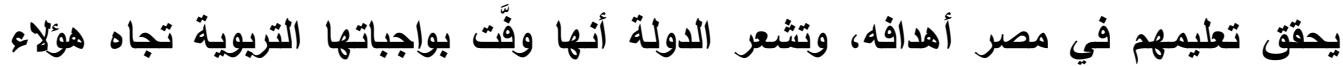

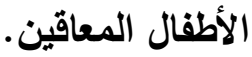

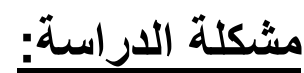
أن الأغلبية من مدارس التربية الخاصة ويرامج الدمج لا تجد الكوادر المؤهلة والمعدة بشكل جيا من المشرفين التربويين والمعلمين والإداريين الذين يستطيعون التعامل بشكل أفضل مع جميع أقطاب العملية التعليمية داخل مدارس التربية الخاصة ويرامج الدمج بالشكل الأي يحقق الهدف المنشود من العملية التعليمية. فضلاً عن القصور الواضح في المناهج والأبنية التعليمية واللوائح المنظمة للعمل بميدان التربية الخاصة. لألك تحددت مشكلة الدراسة الحالية في النقاط التالية : • كثير من ذوي الاحتياجات الخاصة داخل مدارس التربية الفكرية ومدارس النور والأمل ويرامج الامج لا يجدون الكوادر المؤهلة بشكل جيد والذين يستطيعون التعامل وإلتدريس لهم بفاعلية ونجاح، وتحويلهم إلى أفراد ناجحين في المستقبل. وأن من يقوم بالتدريس لهؤلاء الأطفال في الوقت الراهن في مصر، هم معلمون غير متخصصين بالشكل الذي لهي يمكنهم من القيام بدورهم في تعليم وتربية ذوي الاحتياجات الخاصة بشكلٍ فعالٍ. قصور التجهيزات والإمكانات المتاحة في مدارس التربية الخاصة التي يتم فيها تربية لتربية ذوي الاحتياجات الخاصة والنلازمة لترييتهم التربية السليمة. ضعف الاهتمام بالاكتثاف المبكر عن الأطفال من ذوي الاحتياجات الخاصة في

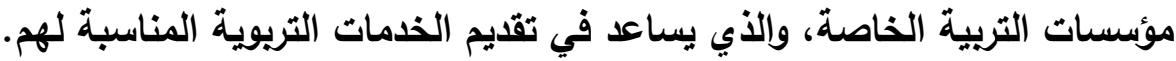
كثيراً ما يتم دمج ذوي الاحتياجات الخاصة داخل فصول التعليم العام دون توفير لهابي الاحتياجات اللازمة لتربيتهم بالشكل المناسب لطبيعتهم ، بالرغم أن لهم ما يميزهم من لن خصائص وأعراض تختلف عن العاديين والتي تستلزم رعاية وتربية من نوع خاص. قصور بعض التشريعات والقوانين التي تهتم بتربية ذوي الاحتياجات الخاصة على

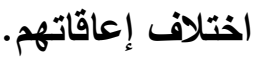

ومن هنا تحددت مشكلة الدراسة الحالية في أن ذوي الاحتياجات الخاصة لا يجدون

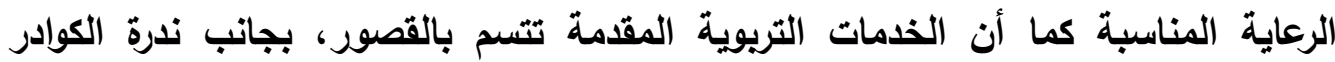


البشرية المدرية والمعدة الإعداد التريوي اللازم للتعامل مع ذوي الاحتياجات الخاصة، والذين يستطيعون تربية هؤلاء الأطفال ويالتالي فهناك احتياج شديد إلى زيادة الاهتمام بتربية ذوي الاحتياجات الخاصة والاستفادة من الخبرات والتجارب العالمية الحديثة في هذا المجال.

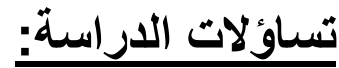
سعت الاراسة الحالية للإجابة على التساؤل الآتي: ما أهم برامج تربية وتعليم ذوي الاحتياجات الخاصة في مصر؟ لهابه وللإجابة عن التساؤل الرئيس للاراسة لابد من الإجابة عن مجموعة من التساؤلات الفرعية الآتية:

س ا: ما مفهوم التربية الخاصةٌ؟، وما أهم الأبعاد؟. س ץ: ما الهيكل التظيمي لتعليم ذوي الاحتياجات الخاصة؟. مهابه س ץ: ما مقومات تربية ذوي الاحتياجات الخاصة في مصر؟؟ س ؛ : ما الروية المقترحة لتطوير برامج تربية ذوي الاحتياجات الخاصة في مصر؟؟ الاجئ

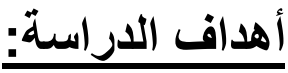
تحددت أهداف الاراسة الحالية في النقاط التالية: التمهيد لتربية ذوي الاحتياجات الخاصة في مصر بشكل تربوي يحسّن البيئة الدراسية ويضمن تكافؤ فرص تعليمية لهوّلاء الأطفال مثل العاديين. التوصل إلى تشريعات وقوانين تضمن بيئة تعليمية لذوي الاحتياجات الخاصة. دفع المسئولين بالتربية الخاصة بالدولة للاهتمام بهذه الفئة المهملة (ذوي الاحتياجات الخاصة) مثل بقية الأطفال. تحديد الصعويات والمعوقات التي تواجه تربية ذوي الاحتياجات الخاصة ورعايتهم في مصر والتعرف على سبل مواجهة تلك الصعويات. وضع تصور مقترح لتربية ذوي الاحتياجات الخاصة بشكل يضمن الد المناسب من من الفرص التعليمية، ويلبي احتياجاتهم الخاصة. 


\section{أهمية الدراسة:}

نبعت أهمية الاراسة والحاجة إليها من عدة جوانب هي:-

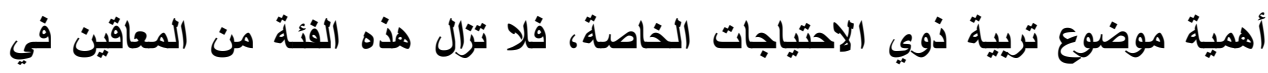

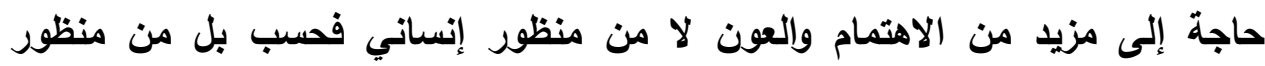
اجتماعي واقتصادي وتريوي أيضاً.

مواكبة الدراسة الحالية للاهتمام العالمي الآن بتربية ذوي الاحتياجات الخاصة، وإدراك الدول والمجتمعات المختلفة لحجم وخطورة مثكلة الإعاقة وكيفية رعاية هؤلاء الأطفال. ذوو الاحتياجات الخاصة في مصر بحاجة إلى مزيد من الدارسات والبحوث التي لئي

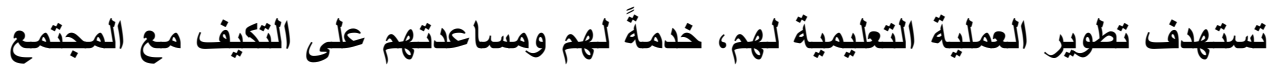
وتحويلهم إلى طاقة منتجة لا مستهلكة.

يمثل ذوو الاحتياجات الذاصة فئة موجودة في أي مجتمع لا يمكن إغفالها أو إهمال حقوقها في الحصول على مختلف الخدمات التريوية والاجتماعية التي تنالها الفئات

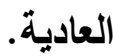

يمكن أن تسهم الدراسة الحالية في زيادة وعى المسئولين عن التربية الخاصة

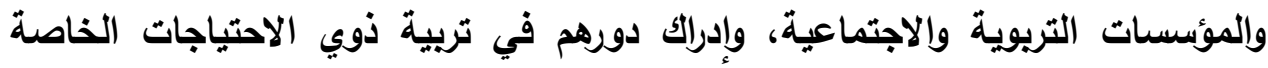
والارتقاء بالذذمات التعليمية المقدمة لهر.

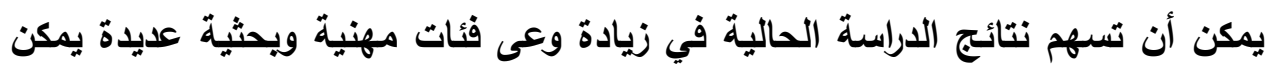
لها أن تترجم هذه النتائج إلى واقع فعلى يسهم في تطوير البرامج التريوية والدراسية لذوي الاحتياجات الخاصة في مصر.

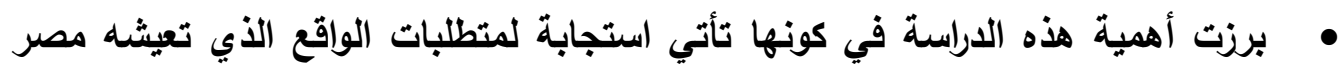

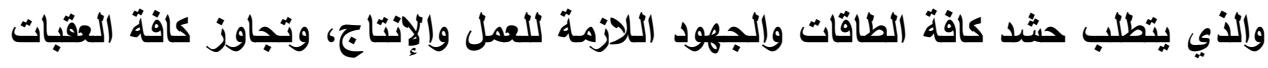
التي تقف في طريق العمل والبناء ومن بينها مشكلة ذوي الاحتياجات الخاصة.

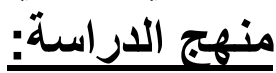

أعتمد الباحث في الدراسة الحالية على المنهج الوصفي باعتباره أسلوب لإيضاح

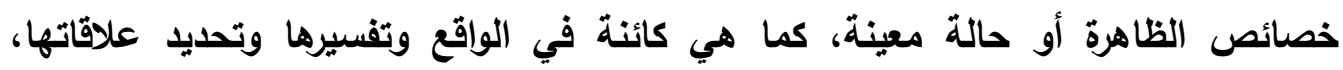

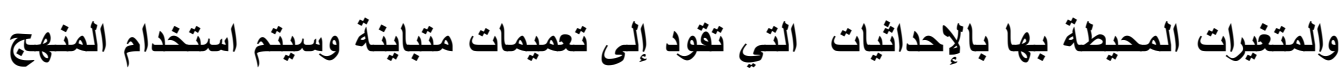


الوصفي في وصف وتفسير النتائج وتحليلها في عبارات واضحة ومحددة للوصول إلى تعميمات والتوصل إلى حلول للمشكلة.

وتم استخدام المنهج الوصفي من خلال الدراسة الحالية فيما يأتي:-

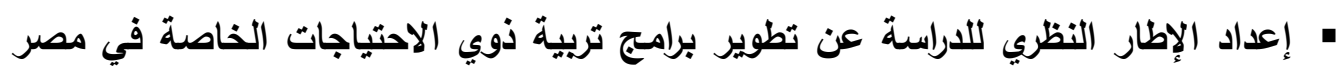
وأبعاد هذه الدراسة وفصولها المتعددة. • يقوم الباحث بتطبيق أداة البحث على عينة البحث وهم؛ مدارس الإعاقة العقلية (مدارس العادئ

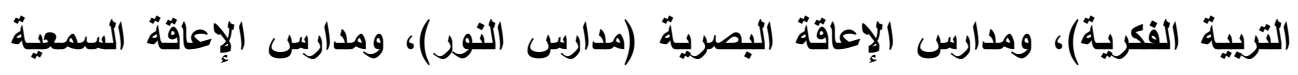
(مدارس الأمل)، والإدارات التريوية والتعليمية للتربية الخاصة.

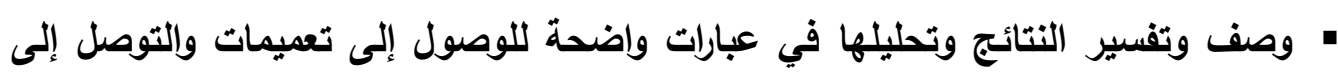

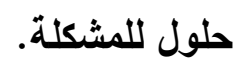
• وضع الروئة لتطوير برامج تربية ذوي الاحتياجات الخاصة في مصر. حدود الارباسة: الروية: اقتصرت الدراسة على مدارس الإعاقة العقلية ( مدارس التربية الفكرية)، ومدارس

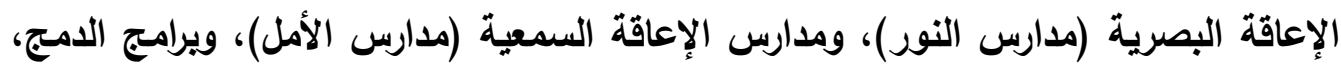

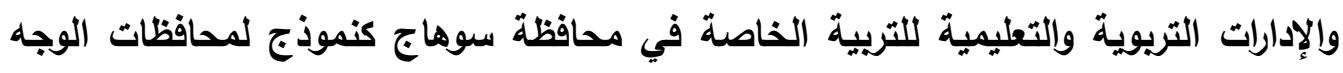
القبلي، وكذلك محافظة القاهرة والإسكندرية كنموذج لمحافظات الوجه البحرية البحري. أداة الار اسة: اعتمد الباحث في هذه الدراسة على المقابلات الغير مقتنة مع القائمين على تربية ذوي

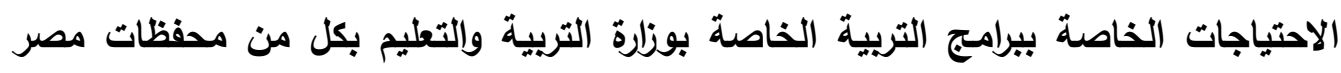

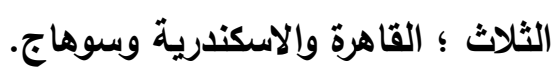
مصطلحات الار اسةة: ذوو الاحتياجات الخاصة

يعرف ذوو الاحتياجات الخاصة بأنهم الأطفال الذين يختلفون عن أقرانهم العاديين في

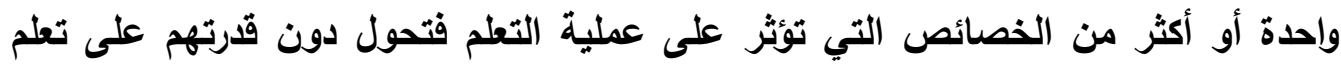

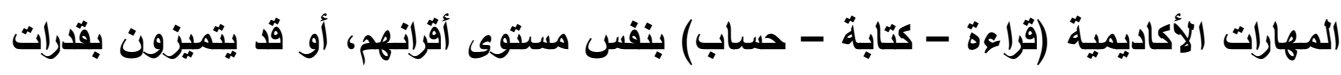

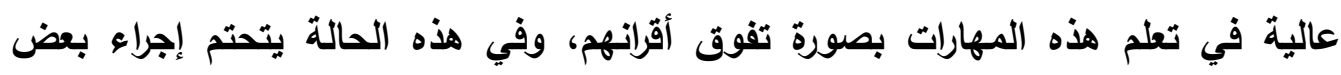


التعديلات في البرامج التريوية والخدمات المقدمة لهولاء الأطفال، أي في برامج التربية

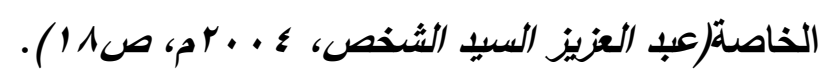

وعرف الباحث ذوي الاحتياجات الخاصة إجرائياً في هذه الدراسة بالأطفال الذين يعانون

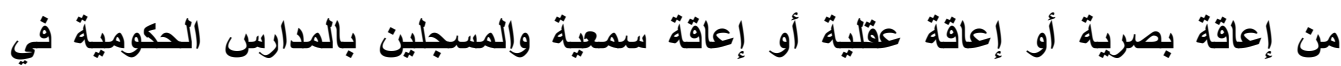
جمهورية مصر العربية.

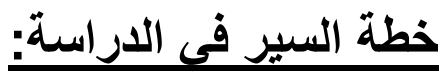

للإجابة عن أسئلة الدراسة الحالية وتحقيق أهدافها، سارت الدراسة وفقاً للإجراءات الآتية: أولاً: تناول الباحث مشكلة الاراسة وأسئلتها وأهميتها وأهدافها ومنهجيتها ومصطئهاتهاتها لهاتها وحدودها وذلك من خلال الجزء الأول من الاراسة بعنوان "الإطار التمهيدي".

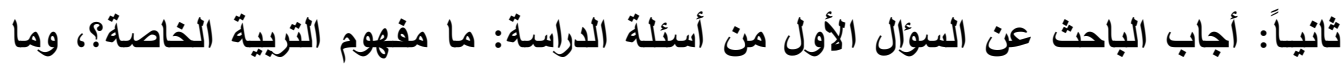
أهم الأبعاد؟. من خلال تخصيص البند الأول من الدراسة بعنوان " التربية الخاصة وأهم

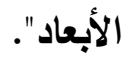
ثالثاً: أجاب الباحث عن السؤال الثاني من أسئلة الدراسة: ما الهيكل التظيمي لتعليم ذوي الاحتياجات الخاصةٌ. من خلال تخصيص البند الثاني من الدراسة بعنوان: " الهيكل من التظظيمي لتعليم ذوي الاحتياجات الخاصة ".

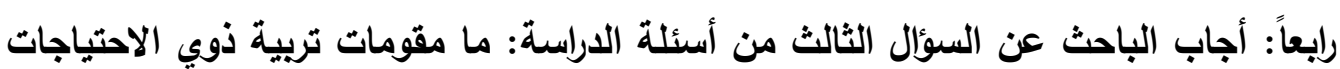

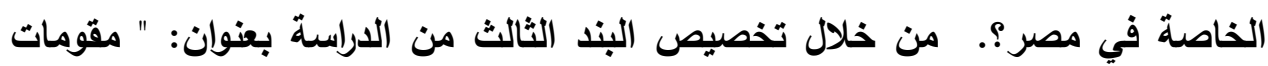
تربية ذوي الاحتياجات الخاصة في مصر". خامساً: أجاب الباحث عن السؤال الخامس من أسئلة الدراسة: ما الروئية المقترحة لتطوير برامج تربية ذوي الاحتياجات الخاصة في مصر؟. من خلال تخصيص البند الخامس من

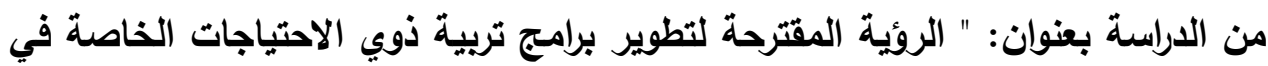




\section{الجزء الثاني \\ الإطار النظري للأراسة الثيأي}

يقوم الباحث بالإجابة عن أسئلة الاراسة من خلال الإطار النظري التالي: أولاً: مفهوم التريبة الخاصة وأهم الأبعاد: (1)مفهوم التربية الخاصة

فيُقَصَد بالتربية الخاصة، أنها مجموعة البرامج والخطط والاستراتيجيات المصممة

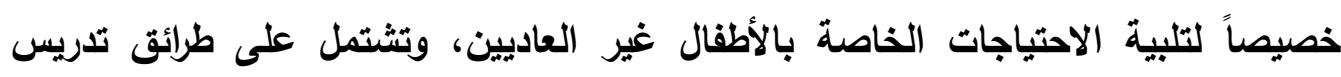
وأدوات وتجهيزات ومعدات خاصة، بالإضافة إلى خدمات مساندة (عبل العزيز الشغص، الاهي،

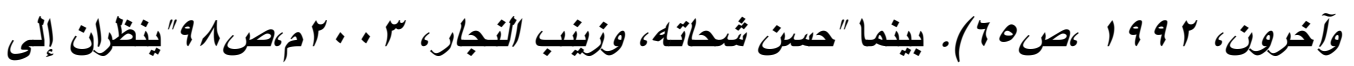

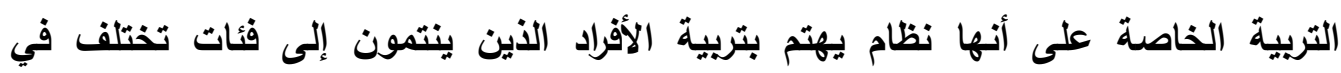
المستوى العادي، سواء كان هذا الاختلاف في الخصائص الجسمية أو العقلية، ومن أمثلة هذه الفئات الصم والبكم والمكفوفون والمتفوقون عقلياً وكذلك ضعاف العقول. أما مصطلح الفئات الخاصة يقوم على أساس أن المجتمع يتكون من فئات متعددة، وأن من بين تلك الفئات فئات تتفرد بخصوصية معينة، ولا يشتمل هذا المصطلح على أي كلمات تثير إلى سبب تلك الخصوصية (عبل العزيز الشخص، وعبل الغفار عبل الحكيم

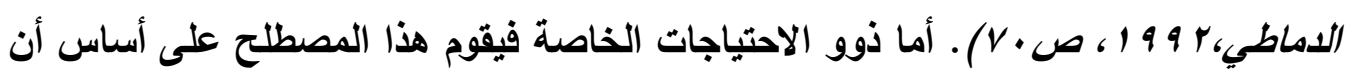

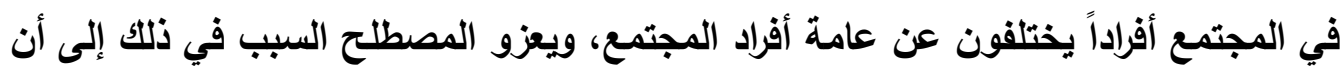
لهؤلاء الأفراد احتياجات خاصة يتفردون بها دون سواهم، وتتمثل تلك الاحتياجات في برامج

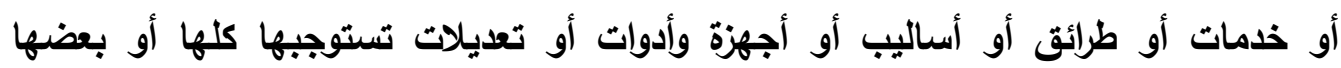
ظروفهم الحياتية، وتحدد طبيعتها وحجمها ومدتها الخصائص التي يتسم بها كل فرد منهم.

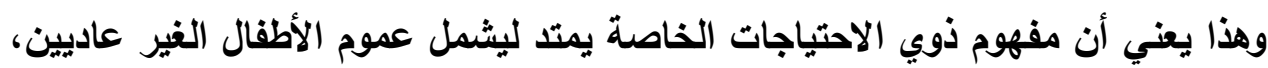

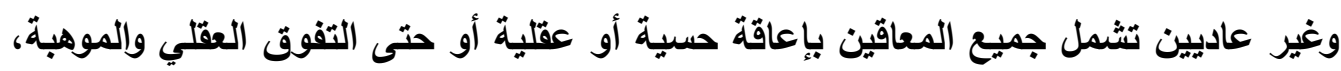

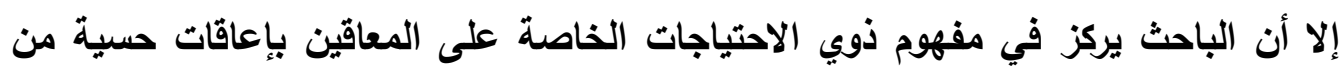

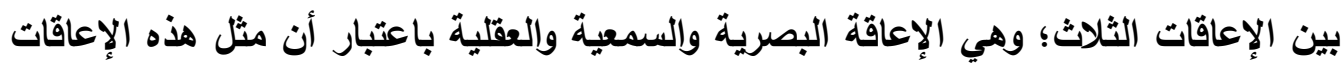
يتم تخصيص مدارس تربية خاصة لهم، وكذلك فصول ملحقة بالمدارس العادية في مصر. 


\section{(r) أهداف التربية الخاصة}

تهدف التربية الخاصة إلى تربية وتعليم ذوي الاحتياجات الخاصة وتدريبهم لاكتساب

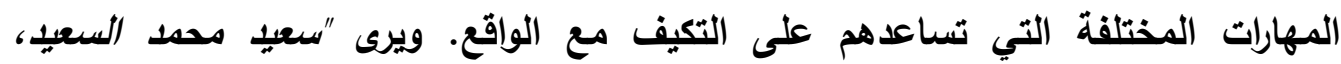
r . . rم، صعه ا" أن أهداف التربية الخاصة تثمثل في الآتي: تحقيق الكفاءة الشخصية: فتسعى التربية الخاصة إلى مساعدة الأفراد ذوي الاحتياجات الخاصة على الحياة الاستقلالية والاكتقاء والتوجيه الأاتي والاعتماد على النفس. تحقيق الكفاعة الاجتماعية: وذلك بغرس وتنمية الخصائص والأنماط السلوكية اللازمة للتفاعل ويناء العلاقات الاجتماعية المثمرة مـع الآخرين. تحقيق الكفاءة المهنية: من خلال إكساب ذوي الاحتياجات الخاصة بعضاً من المهارات البدوية والخبرات الفنية المناسبة لطبيعة إعاقتهم وإستعداداتهم. (r) فلسفة التربية الخاصة وتكمن فلسفة التربية الخاصة للمعاقين في فلسفة التربية السائدة والمستمدة من فلسفة المجتمع، والتي تنعكس في النظام التعليمي وما يقدمه من سياسات موجهة نحو تحقيق أهداف المجتمع، إلا أنها تركز بثكل رئيسي على دراسة وتفعيل التغير السلوكي للأفراد المعاقين(Joan, d. 2002, p121). ويالتالي تمكينهم من الوصول إلى مستويات نجاح عالية، وإكسابهم المعرفة وإلمهارات والقيم المتطلبة ليصبحوا أعضاء مسئولين في مجتمع ديمقراطي، حيث تقوم فلسفة التربية

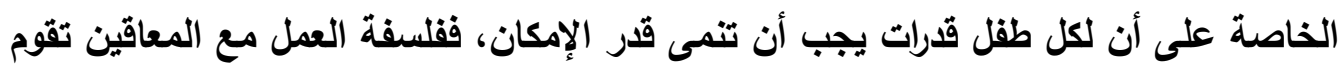
على حقيقة أنه رغم وجود بعض العجز في قدرات الأفراد المعاقين، إلا أن هذا العجز لا يحرم الفرد من كل قدراته وإمكاناته بل قد يكون هناك بعض التعويض في قدرات أخرى تظهر عند

$$
\begin{aligned}
& \text { الفرد ويتفوق فيها إلى حدٍ كبير (كلير فهيم، ه . . rم، صـ A). }
\end{aligned}
$$

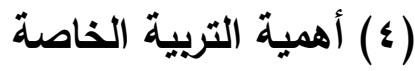

للتربية الخاصة أهمية كبيرة في أي مجتمع لما تقوم به من وظيفة قومية من حيث

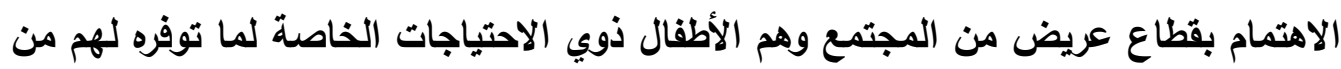

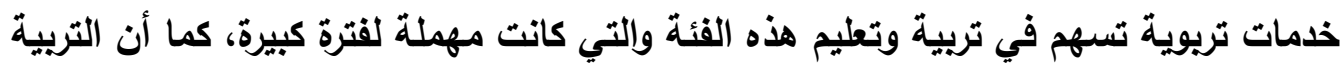
الخاصة لم تظهر أهميتها في الدول العربية ومصر إلا في وقت متأخر وخاصة بعدما ثبت هـت 
للتريويين المتخصصين في مجال التربية الخاصة أهميتها وفعاليتها وخصوصاً في الدول التي كان لها الأسبقية مثل الاول الأوربية. ولقد حظيت التربية الخاصة في الآونة الأخيرة باهتمام كبير لعدة أسباب وهي كالآتي: حاجة المعاقين للرعاية النفسية والصحية لإثعارهم بأنهم أفراد نافعون في المجتمع.

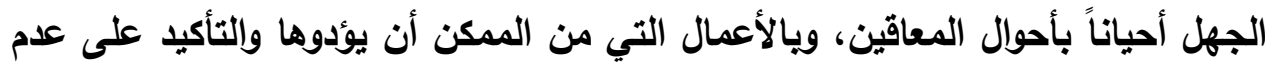

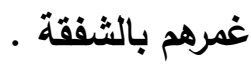
توفير بيئة غنية بالمثيرات للمعاقين. نقل المعاقين من الحالة التي هم فيها إلى وضع أفضل في شتى المجالات. حاجة المعاقين إلى تنمية قراتهم الاعتيادية، وتحقيق الكفاية الذاتية والاجتماعية المهنية والاقتصادية. حاجة المعاقين إلى الإحساس بالرضا والمتعة في الحياة دون أن تعمل الإعاقة على شعورهم باليأس. حاجة المعاقين إلى مساهمتهم في الحياة الاجتماعية وإلنشاطات المتعددة التي تتناسب وإمكاناتهم المختلفة. • حاجة المعاقين إلى تحقيق التوافق الثخصي بحيث يتمكن كل منهم من تكوين علاقات اجتماعية سليمة.

تزايد أعداد ذوي الاحتياجات الخاصة حتى وصلت نسبتهم إلى حوالي ب r 1 \% من مجموع سكان العالم (ونلرة التربية والتعليم، بوابة الغدمات الإلكترونية، 1 ـ . ب م). ثانياً: التهيكل التظيمي لتعليم ذوي الاحتياجات الخاصة في مصر إن تعليم ذوي الاحتياجات الخاصة في مصر يركز بشكل واضح على الإعاقات الرئيسية

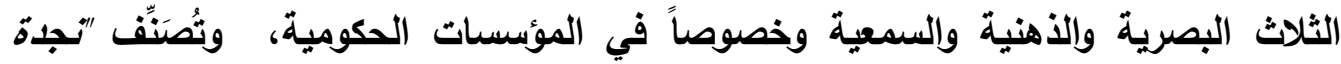
إبراهيم علي، . . . F م،صAN" الهياكل الرئيسية لتعليم ذوي الاحتياجات الخاصة كالآتي: [1] المدارس والفصول الخاصة بالمعاقين بصرياً: (أ) مدارس النور للمكفوفين: • الحلقة الابتدائية من التعليم الأساسي للمكفوفين؛ ومدة الاراسة بها (اسنوات). • الحلقة الإعدادية من التعليم الأساسي للمكفوفين؛ ومدة الإراسة بها (بسنوات). 
• المرحلة الثانوية للمكفوفين؛ ومدة الدراسة بها (ب سنوات). (ب) مدارس وفصول المحافظة على البصر (ضعاف البصر):

الحلقة الابتدائية من التعليم الأساسي لضعاف البصر؛ ومدة الدراسة بها (آسنوات).

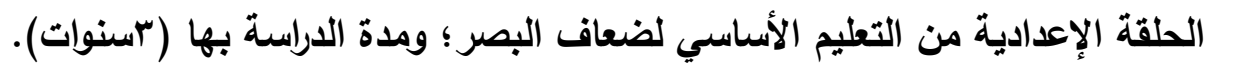

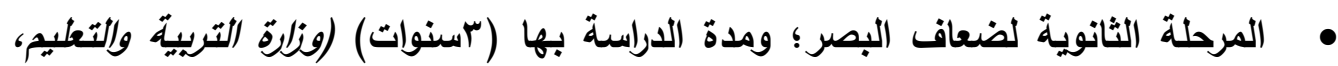

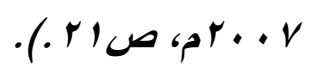

شروط القبول بمدارس وفصول التربية البصرية:

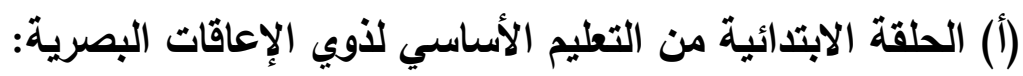

يقبل الأطفال بالصف الأول بهذه المدارس والفصول الأطفال المكفوفين الذين يبلغ سنهم الذهي

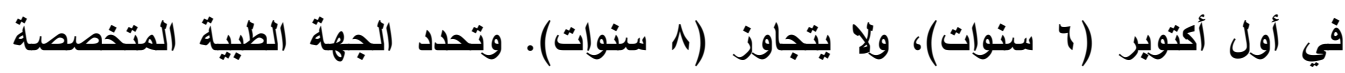
مواعيد الكشف الطبي لكل مدرسة ، على أن يتم الكشف على جميع المتقدمين قبل بلء الاسراسة بوقتٍ كافٍ.

والحالات التي تقبل بهذه المدارس هي: حالات فقد البصر الكلي والأطفال الذين تقل حدة إبصارهم عن (؟/ • ؟) بالعينين معاً أو بالعين الأقوى. وتلاميذ مدارس التعليم العام أو فصول المحافظة على البصر الأين يفقدون بصرهم كلياً وجزئياً ويُحَوَّلون إلى مدارس النور للمكفوفين، يُقبَلُون بشرط تقرير طبي على أن تنظم لهم دراسة خاصة في تعليم طريقتي "برايل" و"بتلر". ولا يُقبّل بهذه المدارس الأطفال المكفوفون الذين لديهم إعاقات أخرى جسمية لهمية أو عقلية أو جسدية أو حسية تقرها الجهة الطبية أو النفسية المختصة. (ب) الحلقة الإعدادية من التعليم الأساسي لأوي الإعاقات البصرية: يُقِّبل بها الناجحون في امتحانات النقل بحيث لا يزيد سن الطالب في أول أكتوير عن (V) العام الذين يفقدون البصر كلياً أو تقل حدة إبصارهم عن (؟/ • ؟) بالعينين معاً، أو بالعين

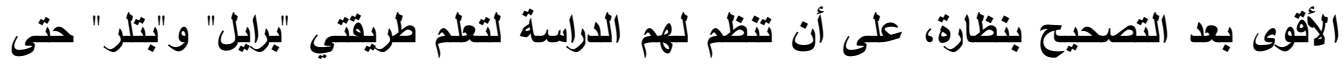
يتسنى لهم مواصلة الدراسة مع التلاميذ المكفوفين، ويجوز قبول تلاميذ جدد في الصفين الثاني والثالث متى استوفوا الثروط السابقة بزيادة سنة عن السنة المقررة لكل صف. 
(ج) المرحلة الثانوية لذوي الإعاقات البصرية:

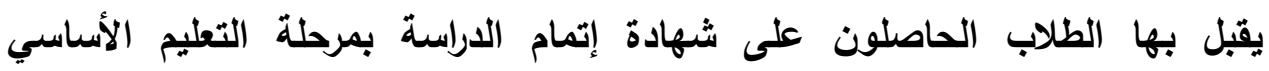

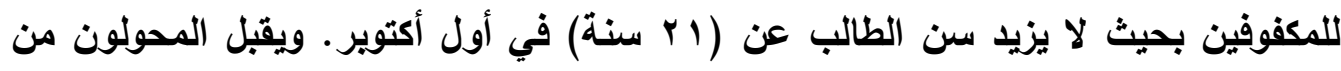

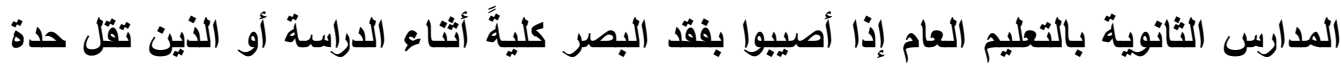

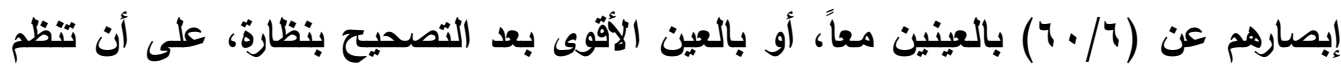

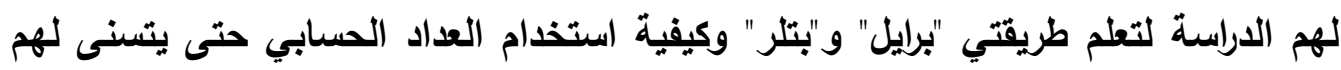

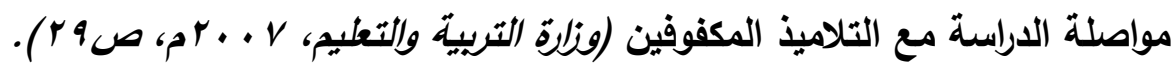

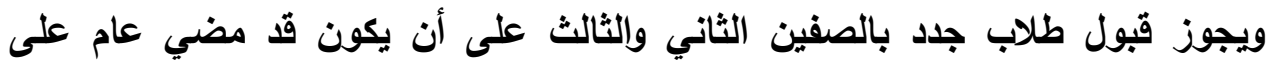

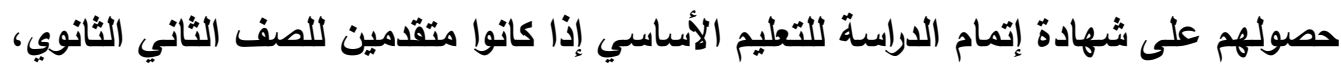

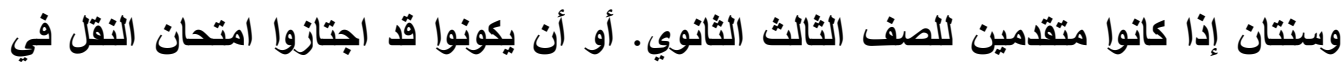

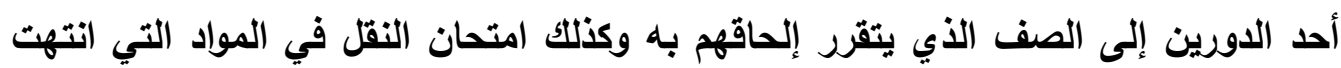

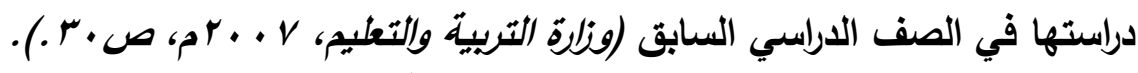
شروط القبول بمدارس وفصول المحافظة على البصر (ضعاف البصرة):

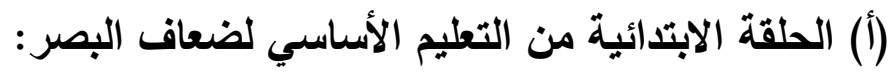

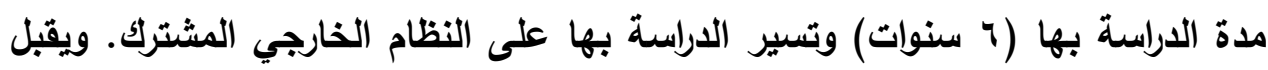

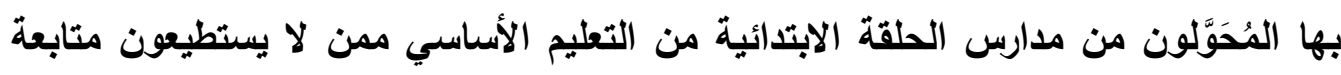

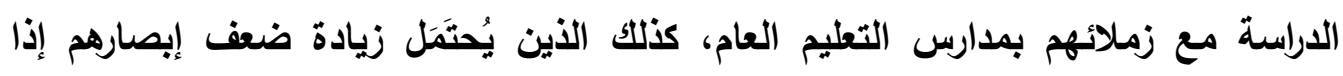

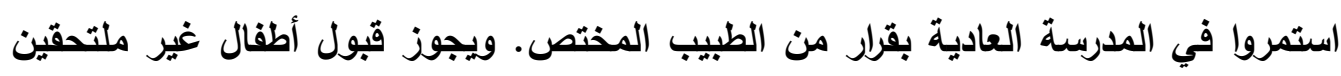

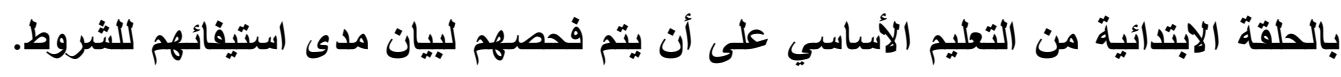

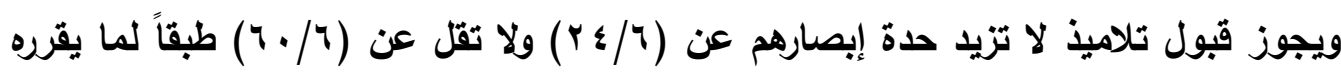

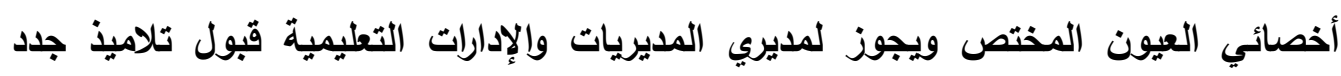

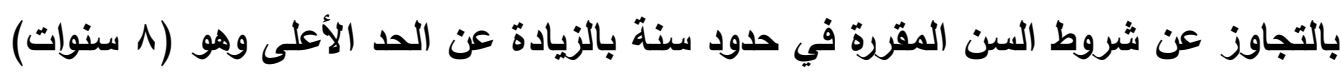

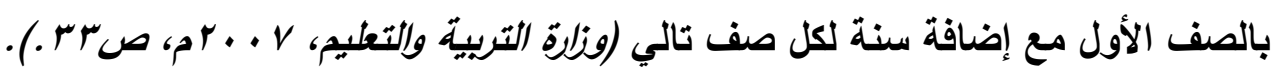

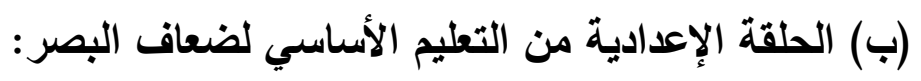

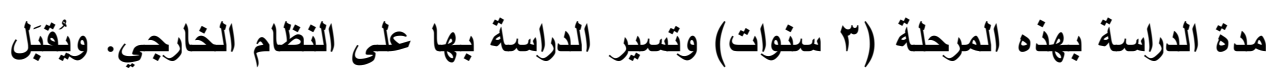

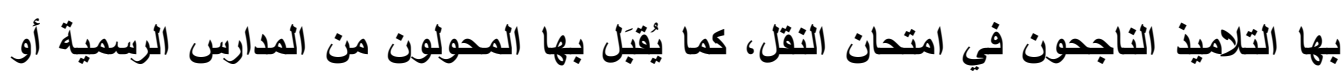


الخاصة بالحلقة الإعدادية من التعليم الأساسي متى ثبت استيفائهم للشروط الطبية الخاصة

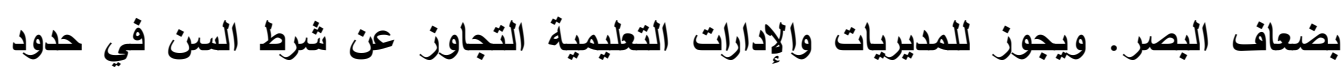
سنتين بالزيادة عن الحد الأعلى المقرر بالصف الأول الإعدادي بشرط لا يزيد السن عن (V) سنة) في أول أكتوير · ويجوز قبول تلاميذ جدد بالصفين الثاني والثالث بالحلقة الإعدادية

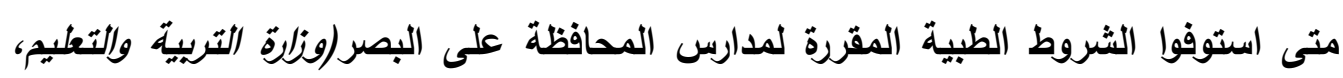

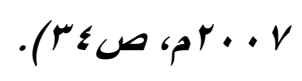

(ج) المرحلة الثانوية لضعاف البصر:

مدة الدراسة بها (ب) سنوات وتسبر الدراسة بها على النظام الخارجي. ويقبل بها التلاميذ الحاصلون على شهادة إتمام الدراسة بمرحلة التعليم الأساسي من مدارس وفصيل بلهول المحافظة على البصر، مع إعفائهم من شروط الدرجات المقرة لتنسيق القبول بالمرحلة الثانوية. كما يُقبَّل التلاميذ المُحَوَّلون من المدارس الثانوية بأنواعها رسمية كانت أو أو خاصة متى استوفوا الثروط الطبية الخاصة بضعاف البصر . ويجوز للمديريات والإدارات التعليمية

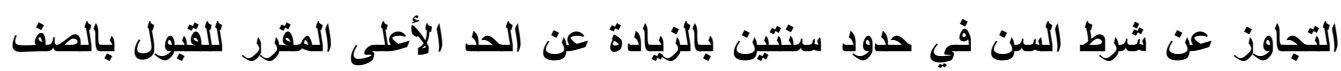

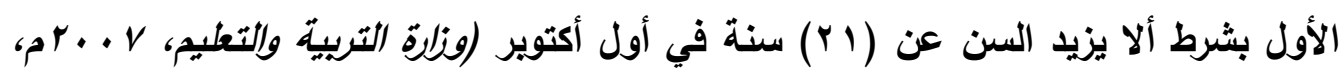

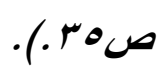

[ץ] [المدارس والفصول الخاصة بالمعاقين سمعياً: تتضمن مدارس وفصول التربية السمعية ما يأتي: (أ) مرحلة رياض الأطفال للصم وضعاف السمع: ويقبل بها الأطفال الصم وضعاف السمع لئه من (ع: 7 سنوات).

(ب) الحلقة الابتدائية بالتعليم الأساسي للصم وضعاف السمع: ومدة الدراسة بهات سنوات).

(ج) المرحلة الإعدادية المهنية للصم وضعاف السمع: ومدة الدراسة بها (ب سنوات). (د) المرحلة الثانوية القنية للصم وضعاف السمع: ومدة الدراسة بها ثلاث سنوات (أحلام رجب عبد الغقار، r . . r م،صء مrr). 
شروط القبول بمدارس وفصول التربية السمعية: وتتحدد شروط القبول بهذه المرحلة فيما يأتي:

(أ) مرحلة رياض الأطفال للصم وضعاف السمع: ويطلق عليها مرحلة (ما قبل العدرسة)

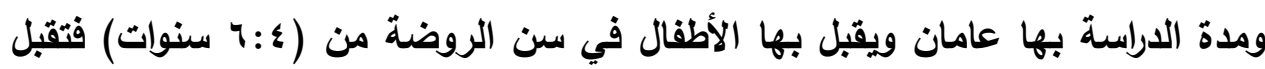
حالات الصمم بجميع أنواعه، وتقوم هذه المرحلة على مستويين أول وثثاني يتعرف الطفل

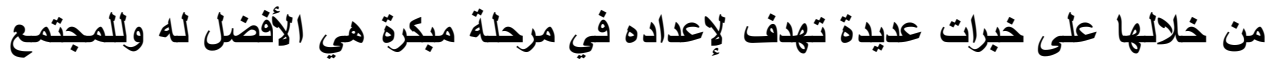

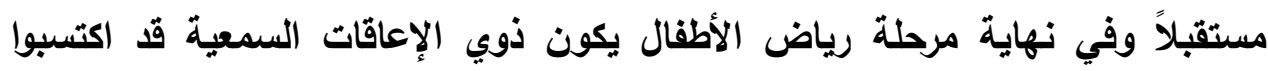

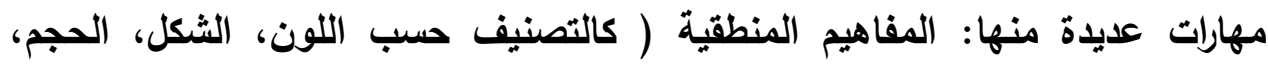
النوع) والتعرف على الأعداد والترتيب والتسلسل والأثكال الهندسية (الجزء والكل)

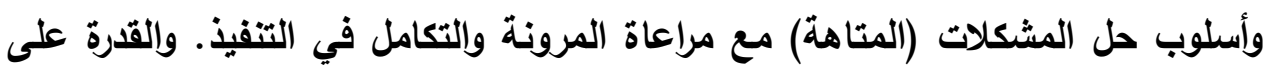
التآزر بين العين واليد وتكوين مشاعر إيجابية نحو الكتابة وزيادة المحصول اللغوي

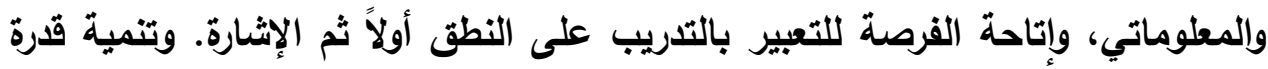

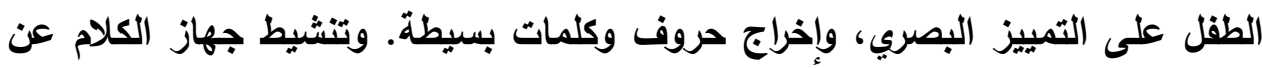
طريق تدريبات النَفَسِ، وتعريف الطقل لذاته وجنسه ومكونات جسمه وبيئته. وتزويدهاه ببعض المهارات اللغوية (ونارة التربية والتعليم (مكتب مستشار التربية الخاصة)،

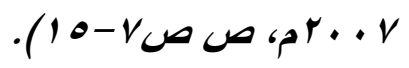
(ب) الحلقة الابتدائية بمرحلة التعليم الأساسي للصم: ومدة الدراسة بها (^ سنوات) والتعليم

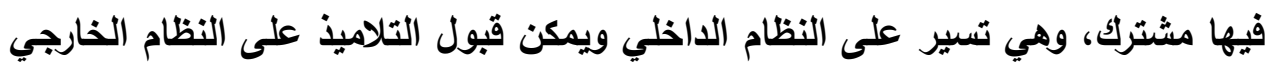

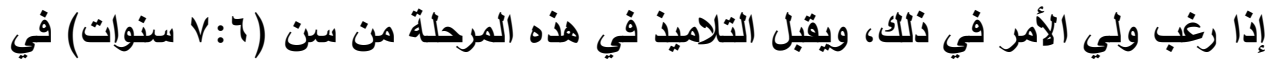
أول أكتوبر ويجوز للمديريات والإدارات التعليمية قبول أطفال جدد في الصف التف الأول في

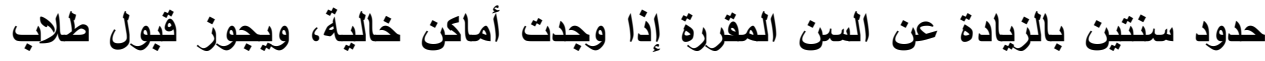
محولين من المدارس العادية في الصفوف المناسبة لأعمارهم ومستواهم التحصيلي بقرار

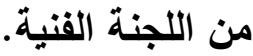

وتقبل بهذه العدارس الحالات الآتية: حالات الصمم بأنواعه: وتثثمل الذين تتراوح عتبة

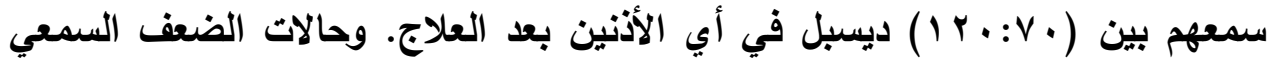

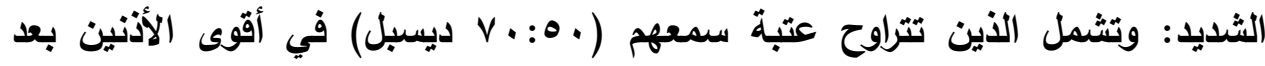

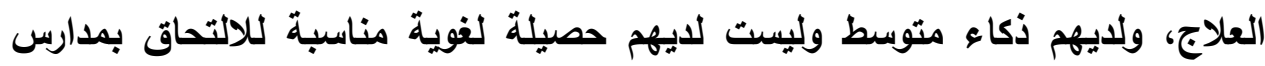


فصول ضعاف السمع، ولا يقبل بمدارس الصم وضعاف السمع الأطفال الذين لديهم قصور عقلي تقرره العيادات النفسية. (ج) الحلقة الابتائية بمرحلة التعليم الأساسي لضعاف السمع: ومدة الدراسة بها (^) سنوات والتعليم فيها مشترك، وهي تسير على النظام الداخلي ويمكن قبول التلاميذ على النظام الخارجي إذا رغب ولي الأمر في ذلك، ويقبل التلاميذ في هذه المرحلة من سن (؟:^)

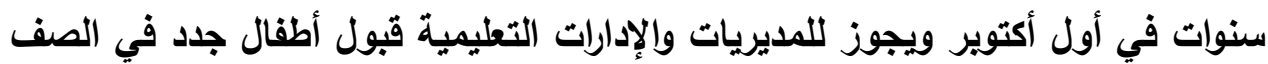
الأول في حدود سنتين بالزيادة عن السن المقررة إذا وجدت أماكن خالية. ويقبل كل المحولين وغير المقيدين بالمدارس الابتدائية على أن تتراوح عتبة السمع ما بين

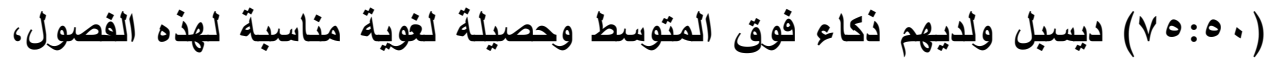
ويتم الكثف الطبي والسمعي والكلامي على جميع المتقدمين. ولا يقبل بهذه المدارس والفصول من لايهم قصور عقلي تقرره الجهات المتخصصة، ويكون الدد الأقصى لسن المقررة بالحلقة الابتدائية من التعليم الأساسي للصم وضعاف السمع (VV) سنة. الحلقة الإعدادية المهنية من مرحلة التعليم الأساسي للصم وضعاف السمع: ومدة الدراسة بها (ساسنوات) وتسير الدراسة فيها على النظام الداخلي والخارجي، ويقبل بها من أتموا الدراسة بالحلقة الابتدائية بمدارس وفصول الصم وضعاف السمع بعد نجاحهم

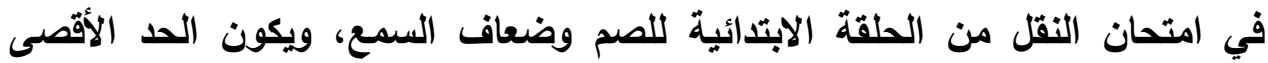
للقبول بالصف الأول الإعدادي المهني للصم وضعاف السمع (vان اسنة) ( ونارة التربية

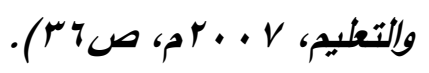

(هـ) المرحلة الثانوية للصم وضعاف السمع: ومدة الدراسة بهذه المدارس (سسنوات)، وتسير الدراسة فيها على النظام الخارجي، ويجوز قبول طلاب فيها على النظام الداخلي إذا رأت الإدارة العامة للتربية الخاصة والمديرية التعليمية المختصة ضرورة لذلك، ويشترط للقبول بهذه المرحلة؛ الحصول على شهادة إتمام الدراسة الإعدادية المهنية من مرحلة التعليم

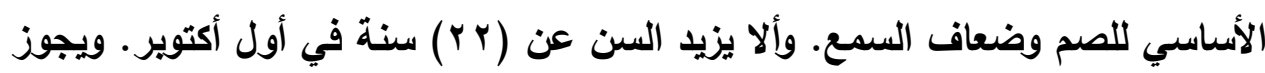
قبول طلاب المدارس العادية والفنية الذين أصيبوا بإعاقة سمعية بشرط حصولثهم على ولى شهادة إتمام الاراسة للتعليم الأساسي. ويجوز قبول الطلاب الذين أصيبوا بصمم أثناء مرحلة التعليم الثانوي العام بحيث يلتحقون بالصف الأول من المرحلة الثانوية الفنية 
للمعاقين سمعياً ومثلهم الطلاب الذين أصيبوا بصمم أثناء مرحلة التعليم الثانوي الفني. ولا يتم القبول بهذه المرحلة إلا بعد إجراء الفحوص الطبية الكاملة بذنياً وعقلياً وسمعياً

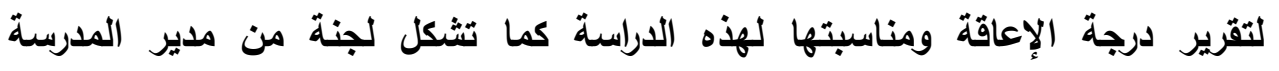
والأخصائَيَّن النفسي والاجتماعي، وعضوين من هيئة التدريس أحدها ثقافي والآخر

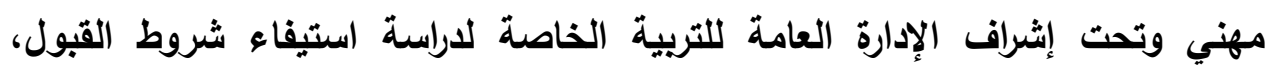
وتصنيف المقبولين، وتوزيعهم على التدريبات المهنية المناسبة لقدراتهم، ويفضل أن الن النيات يكون ذلك امتداداً للمجالات التي أتموا دراستها خلال سنوات دراستهم في الحلقة

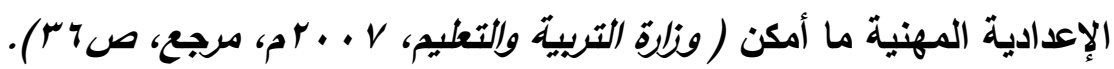
[r]] مدارس وفصول المعاقين عقلياً: توفر الدولة للمعاقين عقلياً من البدائل التريوية والتي تثمل مدارس وفصول للتربية الفكرية، وتسير الدراسة للتعليم الأساسي لذوي الإعاقات العقلية كالآتي: • فترة تهيئة: ومدتها سنتان وخطة الدراسة فيها عبارة عن تدريبات حسية وعقلية وفنية ورياضية، وموسيقية.

• الحلقة الابتدائية: ومدتها (؟) سنوات تتضمن حلقتين كل منهما (ץ) سنوات وخطة الاراسة تتضمن المواد الثقافية البسيطة والمواد العلمية المناسبة. الإعداد المهني: ومدة الدراسة بها (r) سنوات وخطة الدراسة تتضمن التدريبات المهنية بما يتناسب وميول وقدرات التلاميذ والبيئة المدرسية. شروط القبول بمدارس وفصول الإعاقة العقلية: يقبل الأطفال المعاقين عقلياً الذين يتم تحويلهم إليها من المدارس الابتدائية أو ممن لم

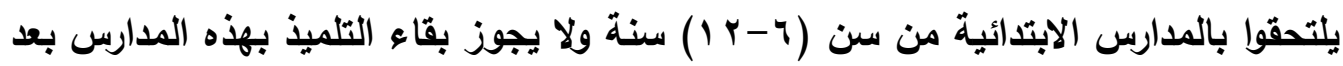
بلوغه سن (1 ا ) سنة في أول أكتوير من العام الدراسي. ويجب أن تتوفر في التلميذ الثروط الطبية والنفسية للقبول بهذه المدارس ومنها؛ أن تتراوح نسبة ذكاء المقبولين بين ( •.: • V) درجة ذكاء. وألا يكون لدى المقبولين إعاقات

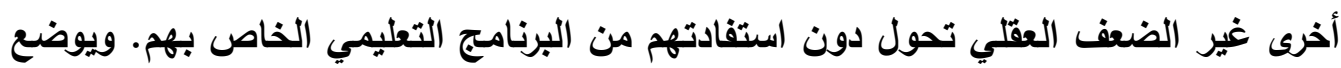

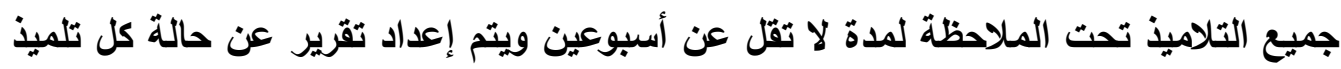
أثناء الملاحظة يرفق بأورلق التحويل إلى العيادة النفسية. ولا يتم القيد النهائي بالمدرسة إلا عن اعن 
بعد إجراء الاختبارات النفسية والفحوص التي تقوم بها الجهات المختصة وذلك بعد أن يتم استيفاء الشروط السابقة(ونلارة التربية والتعليم، قرل ونلاري ققم (V I I)، مادة (IVN)).

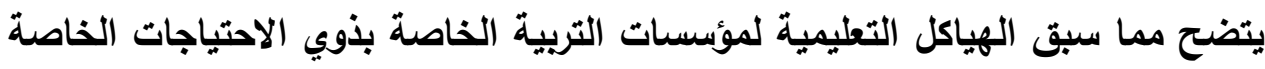
بإعاقاتهم الثلاث؛ سواء الإعاقة البصرية "مدارس النور" أو الإعاقة السمعية "مدارس الأمل" والإعاقة العقلية "مدارس التربية الفكرية"، كذلك يتضح اتجاه الدولة نحو مد مظلة التربية الخاصة نحو دمج ذوي الاحتياجات الخاصة مع العاديين بمدارس التعليم العام.

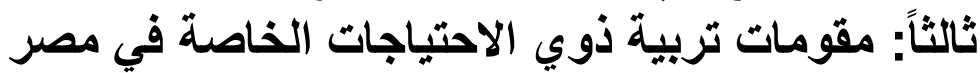
وسيتناول الباحث أبرز مقومات تربية ذوي الاحتياجات الخاصة في مصر كالآتي: (1) (الإدارة التريوية لذوي الاحتياجات الخاصة:

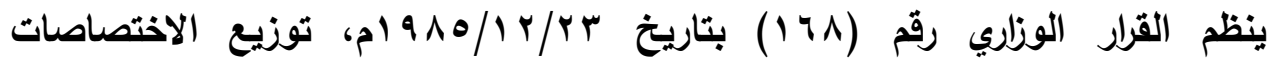
والمسئوليات على أجهزة الديوان العام لوزارة التربية والتعليم ومن بينها الإدارة العامة للتربية

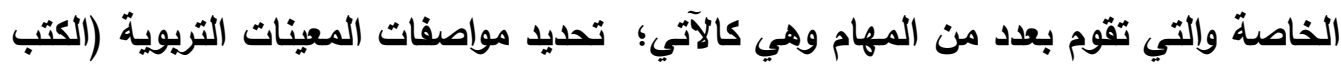
وغيرها لكل فئات المعاقين. واقتراح الخطط والمناهج الخاصة بكل فئة من فئات المعاقين في مختلف المواد الدراسية، وإعداد الدراسات المقارنة عن نظم وأساليب تعليم المعاقين في البلاد المختلفة، واقتراح الموازنات السنوية للمدارس وإعداد النشرات وإلقرارات اللازمة لتنفيذ الخطط والمناهج المقررة، واقتراح نظم الامتحانات وتقييم نتائجها وإعداد ونشر التوجيهات الفنية اللازمة لتعليم كل فئة من فئات المعاقين، والقيام بعمليات التوجيه الفني وتقييم المدارس وأعضاء هيئة التدريس. وكذلك متابعة الخرجين وتوفير فرص عمل لهم واقتراح الخطط والمناهج الخاصة بإعداد المعلمين والمعلمات، واقتراح الخطط والمناهج التدريبية اللازمة للعاملين في مجال التربية الخاصة، واقتراح البعثات اللازمة في التخصصات المختلفة في مجال التربية الخاصة. وتحديد الأعداد اللازمة للمدارس والفصول من أعضاء هيئة التدريس لإئسات والأخصائيين وغيرهم، وإعداد المشروعات الخاصة بالتوسع في إنشاء مدارس وفصول

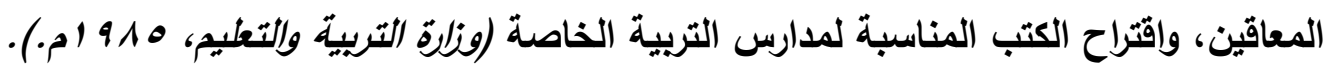
(Y)معلم ذوي الاحتياجات الخاصة: لا يمكن لأي جه تريوي يستهدف الإصلاح والتطوير أن يقلل من أهمية دور المعلم لأنه أحد المدخلات الرئيسية في توجيه التطوير التريوي، وهذا يعني أنه حتى وإن توافرت مباني 
مدرسية ومناهج ووسائل وتقنيات حديثة فإنها لن تستطيع أن تحدث التطوير المطلوب دون

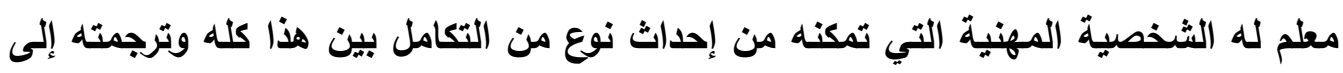
مواقف تعليمية جيدة، فيعتبر إعداد وتأهيل معلم التربية الخاصة ضروري لمساعدة ورفع أداء

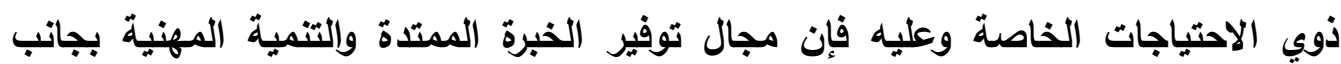

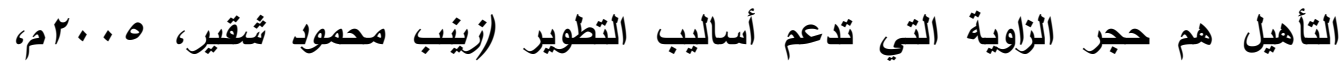
ص

وتكون أفضلية الترشيح للمعلمين من الفئات الحاصلين على البعثة الداخلية لإعداد معلمي المرحلة الإعدادية والثانوية بمدارس وفصول المعاقين بصرياً ومدتها عام للحصول على شهادة الدراسات التخصصية في تربية وتعليم المكفوفين وضعاف البصر . وتحدد وزارة التربية والتعليم شروطاً لقبول المعلمين بالبعثة الداخلية ومن أهمها: أن يكون المتقدم من فن الحاصلين على مؤهل جامعي أو التأهيل التريوي. وتكون أفضلية الترشيح للأصغر سناً. وأن يكون المرشح من العاملين بمدارس أو فصول التربية الخاصة. وأن يجتاز المتقدم الاختبار

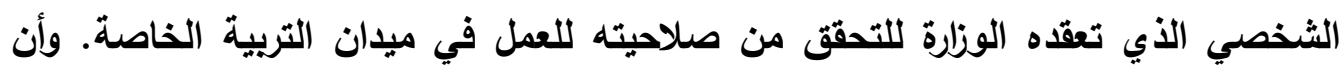

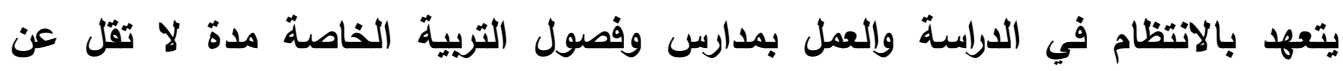
(باسنوات)، ويتقاضى المعلم راتبه أثناء البعثة الداخلية، والمقر الوحيد للبعثة لجميع العاملين

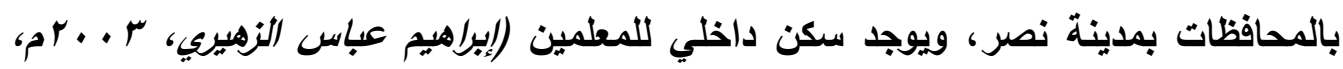

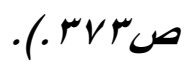
(r) المبنى المدرسي لأوي الاحتياجات الخاصة: للمبنى المدرس أهمية خاصة في تربية وتعليم ذوي الاحتياجات الخاصة، وعلى الرغم من

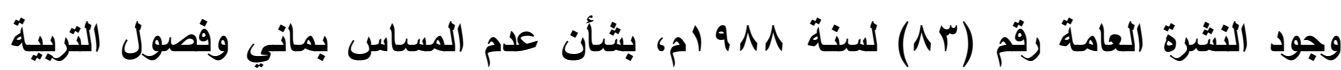

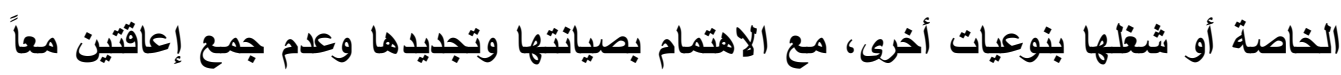

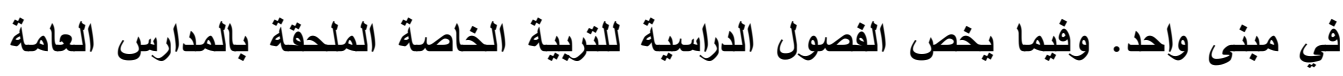
يراعي ألا تقل مساحة الفصول عن (؟×ه) أمتار وأن تكون التهوية جيدة والإضاءة كافية. وضرورة إعداد فصل تعليمي بمدارس النور يخصص لتعليم الكتابة على الآلة الكاتبة بالخط

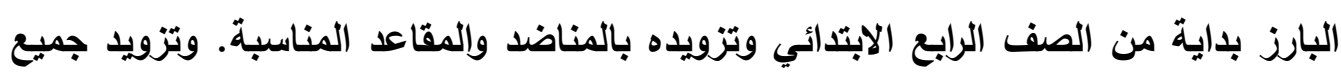

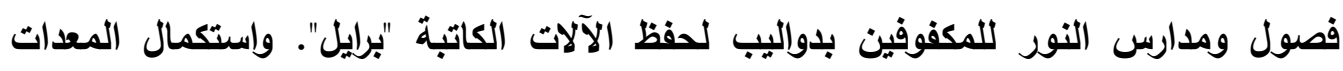


والخامات لورش المجالات بمدارس الأمل للصم وضعاف السمع والتربية الفكرية. والاهتمام بمعامل العلوم والحرص على تزويدها بما يتلاءم والمناهج الحديثة (وزلاثة التربية والتعليم،

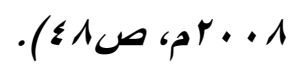

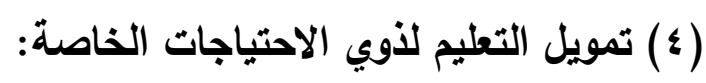

يعتبر تمويل التعليم أحد مدخلات التعليم الهامة باعتباره الأداة الرئيسية لكفل الموارد

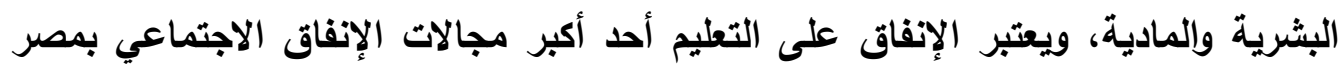
باعتباره من عوامل تحقيق كفاءة التعليم وتطويره، فبدون التمويل اللازم لا يفي التعليم بتحقيق أهدافه، وتلعب السياسة العامة للاولة دوراً مهماً في تحديد ما يخصص للتصني للتعليم من الموازنة العامة وتمارس وزارة المالية نفوذاً كبيراً على ميزانيات الوزارات المختلفة، ومنها وزارة

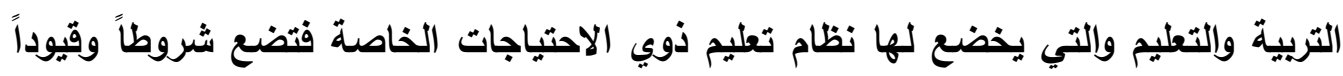

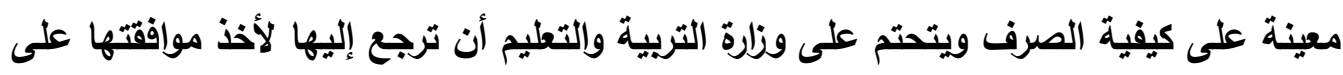

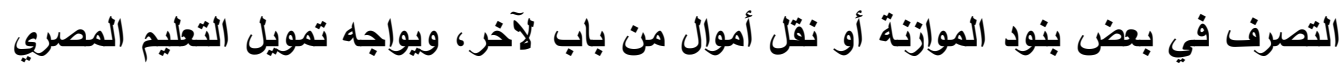

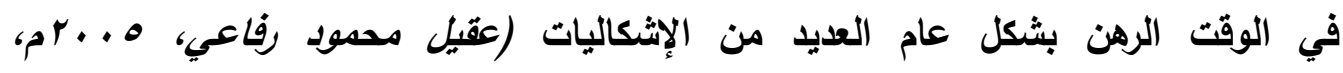
ص (1) (0) الإشراف التريوي والمتابعة والتقويم: (1) ينظم عمليات الإثراف القني والتوجيه وتقويم هيئات التتريس بمدارس وفصول التربية

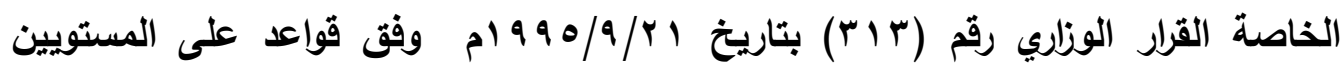
المركزي والمحلي، فعلى المستوى المركزي: تقوم الإدارة العامة للتربية الخاصة بالوزارة بالإشراف الفني والتوجيه والتقويم والمتابعة الفنية بمدارس التربية الخاصة على المستوى الإدرى المركزي كما تتولى تقييم الأخصائيين النفسيين بهذه المدارس والفصول الملحقة. أما على بلى بلى المستوى المحلي: حيث تدخل مدارس وفصول التربية الخاصة بالإدارة التعليمية في نصاب تلوني موجهي الأقسام وموجهي المواد الدراسية بالتعليم الأساسي والمرحلة الثانوية ويشترك بلائ المتخصصون منهم في حالة توفرهم بالإدارة التعليمية كل حسب تخصصه في مجال الإعاقة

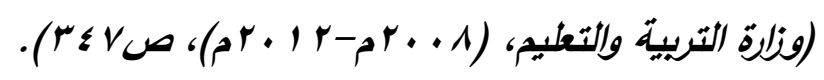


(†) (†ناهج ذوي الاحتياجات الخاصة: تنظق مناهج تعليم ذوي الاحتياجات الخاصة من الفلسفة التعليمية التي يتبناها النظام

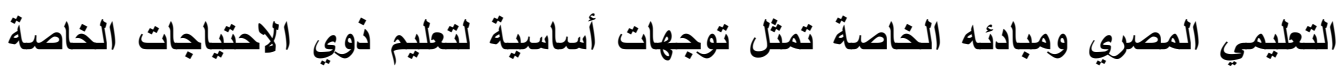
ومنها: اعتبار تعليم ذوي الاحتياجات الخاصة حق تكفله الاولة وليس من قبيل الثيل الثفقة

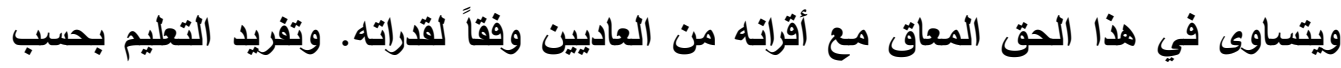

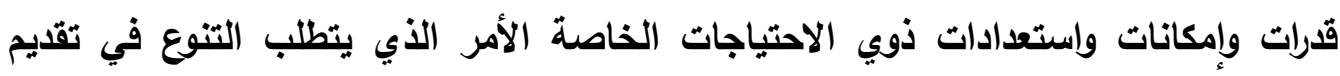
الخبرات التربوية والتعليمية وطرق التريس والأنثطة المختلفة. وتبنى المنهج مبأ تكامل الخبرات التعليمية والتريوية وتوظيفها من خلال مواقف حياتيه. وشمولية الخبرات بحيث

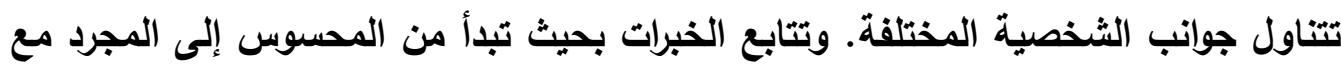
ضرورة تنوعها وذلك في حدود قدرات وإمكانات ذوي الاحتياجات الخاصة. مستخلص وتعقيب على الإطار النظري:

ومن خلال المقابلات التي أجراها الباحث مع مشرفي التربية الترائية الخاصة، وكنلك معلمي التربية الخاصة وهيئات الإدارة بيرامج التربية الخاصة في محافظات مصر الثُاث؛؛ سوهاج والقاهرة والإسكندرية توصل الباحث إلى أن جميع من تم إجراء مقابلة معهم أجمعوا على فلى فئل

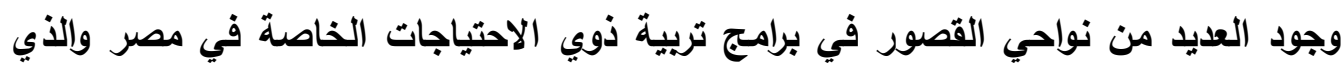
كان من أبرز نواحي القصور فيها ما يأتي: عدم توافر مدارس متخصصة في مصر تغطي جميع الأطفال المعاقين. هناك دور سلبي لوسائل الإعلام فيما يتعلق بالتغطية اللازمة لقضية ذوي الاحتئية الاحتياجات

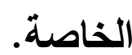
قصور في وزارة الصحة في الكثف المبكر عن ذوي الاحتياجات الخاصة والتعرف عليهم. قلة الأماكن الترفيهية التي تناسب ذوي الاحتياجات الخاصة وعدم توفيرها من قبل

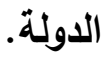
قلة البرامج التعويضية التريوية والتعليمية اللازمة والمفيدة ذوي الاحتياجات الخاصة. هناك قصور في التواصل بين المدرسة والأسرة. 
لا يوجد تواصل بين الوزارات المصرية المختلفة فيما يقدم الفائدة لذوي الاحتياجات الخاصة.

القصور في دور المدرسة في إقامة ندوات تثقيفية لأسر أطفال ذوي الاحتياجات الخاصة.

ضعف دور الجمعيات الأهلية في توعية الجماهير حول طبيعة ذوي الاحتياجات الخاصة. قلة الاستفادة من الأبحاث والدراسات التي تنتجها الجامعات ومراكز الأبحاث فيما يفيد ذوي الاحتياجات الخاصة. عدم وجد أقسام للتربية الخاصة كافية لذوي الاحتياجات الخاصة بكليات التربية في مصر .

القصور في برامج تدريب المعلمين أثناء الخدمة بمدارس التربية الخاصة. عدم تحري الدقة في اختيار المعلمين المناسبين للتدريس ذوي الاحتياجات الخاصة.

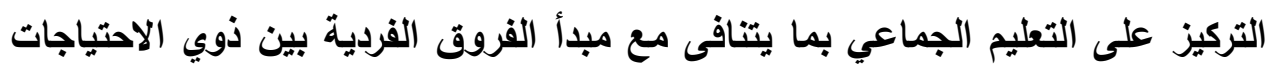
الخاصة.

هناك قصور في التخطيط للبرامج التعليمية لذوي الاحتياجات الخاصة لاى إدارة المدرسة. عدم توافر الروئة الواضحة حول تربية ذوي الاحتياجات الخاصة لاى إدارة التربية الخاصة. الاعتماد على التدريس الجماعي مع المعاقين عقلياً وعدم التتوع في استخدام الأساليب. عدم التركيز بشكل واضح على الخطة التربوية والتعليمية داخل برامج التربية الخاصة. عدم التركيز من قبل مدارس التربية الخاصة على المهارات الفنية مثل الرسم والموسيقى. القصور في المرافق الترفيهية داخل المدارس. عدم مناسبة معظم فصول التربية الخاصة للمقاييس العالمية. لا تهتم إدارة التربية الخاصة بالاستفادة من التطبيقات الحديثة لتربية ذوي الاحتياجات الخاصة. عدم الاهتمام بالتدريب المهني لذوي الاحتياجات الخاصة بما يناسب قدراتهم وميولهم. 
• علام الاستفادة من خبرات بعض الدول في مجال ذوي الاحتياجات الخاصة.

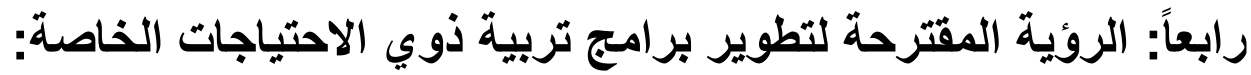

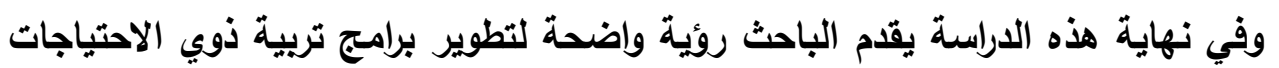
الخاصة. والعمل على إيجاد الحلول العلمية لمشكلاتهم التي تمثل عوائق وقيود تمنعهم من ممارسة الحياة المنتجة في مجتمعاتهم، لذلك فمن المهر بل الأكثر أهية أن يُعاد النظر في

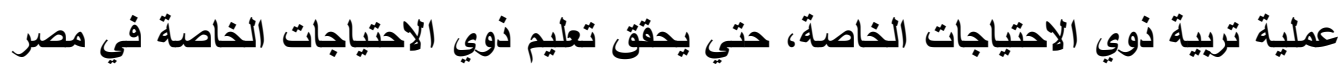
أهدافه، وتثعر الدولة أنها وفَّت بواجباتها التربوية تجاه هؤلاء الأطفال المعاقين. ويمكن تنفيذ الجوانب المقترحة لتطوير الإثراف التريوي لذوي الاحتياجات الخاصة كما يلي:

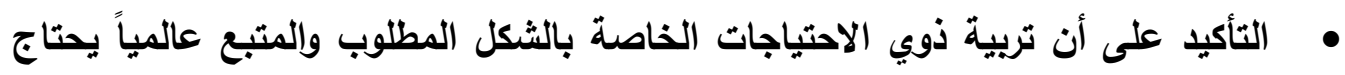
إلى مزيد من الوقت والجها والتظلب على العقبات التي تقف في سبيل تربيتهم بالثكل

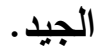
التنمية الثاملة للمجتمع المصري لا تتم إلا بخلق جيل مبلاع قادر على مواكبة التغيرات الحليثة والمتلاحقة، لذلك لا يمكن تحقيق هذه التنمية وهناك إهمال لذوي الاحتياجات الخاصة في هذا المجتمع. الاطلاع على الخبرات العالمية الحديثة في مجال تربية ذوي الاحتياجات الخاصة

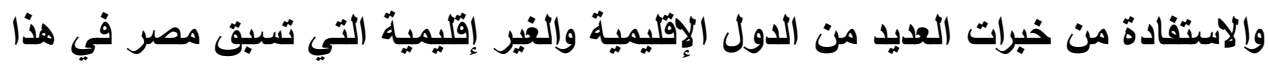
المجال والاقتباس من هذه الخبرات. الاستفادة من الإمكانات العلمية المصرية في المجال التريوي في صياغة منظوانة

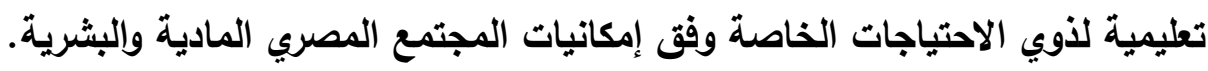
توفير بيئة تعليمية مناسبة لذوي الاحتياجات الخاصة.

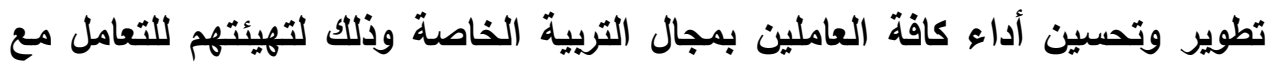
ذوي الاحتياجات الخاصة.

توفير الاعم المادي والمعنوي الذي يكفل تعليم مناسب لذوي الاحتياجات الخاصة.

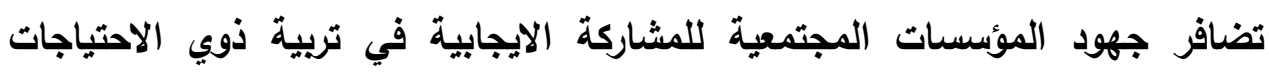

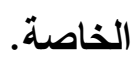

تفعيل دور أولياء الأمور ودفع الأسرة لان تكون شريك في ذوي الاحتياجات الخاصة.

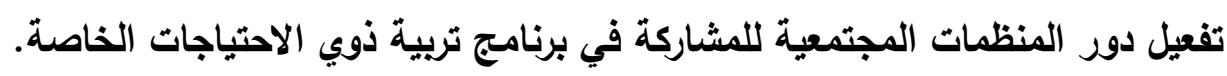


تطوير عملية التدريب المهني للهيئة الإدارية القائمة على تربية ذوي الاحتياجات الخاصة.

توعية مؤسسات المجتمع بأهمية تربية ذوي الاحتياجات الخاصة وفق آليات علمية حديثة.

دفع المخططين والمختصين إلى وضع خطط لتربية ذوي الاحتياجات الخاصة ذات أهداف قصيرة وطويلة الأمد. إلزام إدارات التربية الخاصة بعمل دورات تدريبية للعاملين بمجال التربية الخاصة حول تربية ذوي الاحتياجات الخاصة وكيفية التعامل مع هؤلاء الأطفال. تفعيل أنشطة المدارس المجتمعية من خلال قرارات حكومية من وزارة التربية والتعليم تضمن من خلالها عملية دمج مجتمعي بين المدرسة والمجتمع المحلي المحيط. تعميم أقسام التربية الخاصة بكليات التربية بمصر لتربية ذوي الاحتياجات الخاصة.

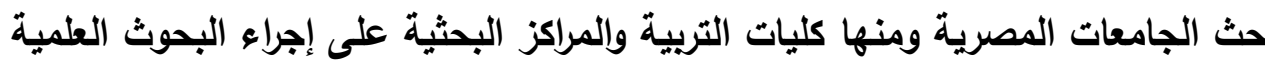
ذات الصلة بذوي الاحتياجات الخاصة من أجل التظلب على مشكلات هؤلاء الأطفال. تغطية وسائل الإعلام بشكل جيد قضية ذوي الاحتياجات الخاصة أمام الجماهير المصرية، وعرض وسائل الوقاية من هذه الإعاقة أو الحد منها على الأقل.

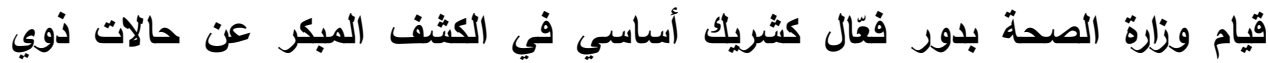
الاحتياجات الخاصة وخاصة في إجراءات قبول التلاميذ في بلاية كل عام. إعداد مشروعات قوانين من اللجان الاستثارية بوزارة التربية والتعليم تكفل تعليم جيد بلهي ومناسب لذوي الاحتياجات الخاصة وعرض مشروعات القوانين على البرلمان المصري

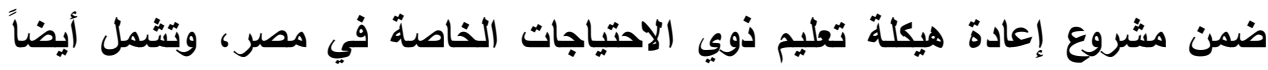
كيفية دمج ذوي الاحتياجات الخاصة مع العاديين بالثكل الملائم لطبيعة إعاقتهم. الإعداد لمؤتمر ثانوي لإدارة التربية الخاصة بالاشتراك مع كلية التربية بكل محافظة لتوعية المواطنين والعاملين بمجال التربية الخاصة بطبيعة ذوي الاحتياجات الخاصة. 
واقع برامج تربية وتعليم ذوي الاحتياجات الخاصة فى مصر ...

خاتمة:

قام الباحث في هذا البحث " واقع برامج تربية وتعليم ذوي الاحتياجات الخاصة في

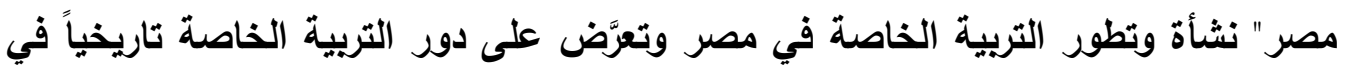

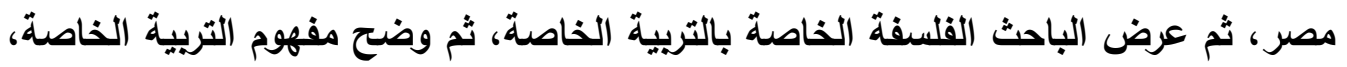

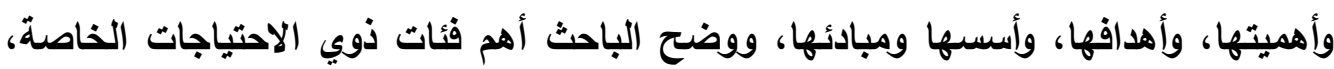
وأنماط وأطر تربيتهم وتطليمهم في مصر، وكنلك وضح الباحث أهم مقومات تربية الأطفال ذوي الاحتياجات الخاصة في مصر، كما قدم الباحث في نهاية الدراسة مرنكزات للتصور المقترح حول تربية ذوي الاحتياجات الخاصة في مصر لمرك.

- |r|1- 
المراجع

إبراهيم عباس الزهيري، "الارتقاء بفعالية الاتصال لاى المعاقين سمعياً في ضوء فلسففة التربيـة

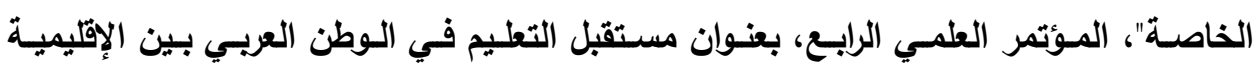

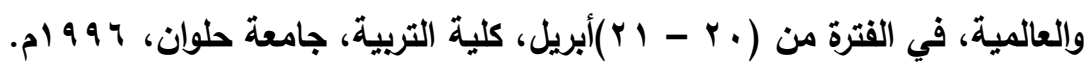
أحلام رجب عبد الغفــر، الرعايـة التربويـة لذوي الاحتياجـات الخاصـة، القـاهرة: دار الفجر للنشـر والتوزيع، ب. . بام.

حسن شحاته، وزينب النجار، معجم المصطلحات التريوية والنفسية، القاهرة: الدار المصرية اللبنانية،

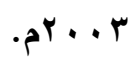
زينب محمود شقير، خدمات ذوي الاحتياجات الخاصة (الدمج - التدخل المبكر - التأهيل المتكامل)،

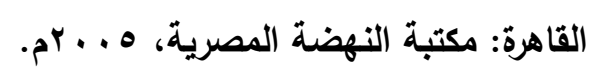
سعيد محمد السعيد، برامج التريبة الخاصة ومناهجها بين الفكر والتطبيق والتطوير، القاهرة: عالم

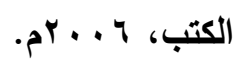

سيد خير الله، ولطفي بركات، سيكولوجية الطفل الكفيف وتريته، القاهرة: مكتبة الأنجلو المصرية، . $197 \mathrm{~V}$

عبد العزيز السيد الثخص، الأطفـال ذوو الاحتياجـات الخاصـة وأسـاليب رعايتهم، القـاهرة: مكتبة

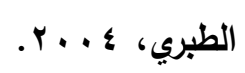

عبد العزيز السيد الثخص، وآخرون، قاموس التربية الخاصة وتأهيل غير العاديين، القاهرة: مكتبة

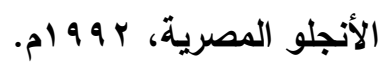

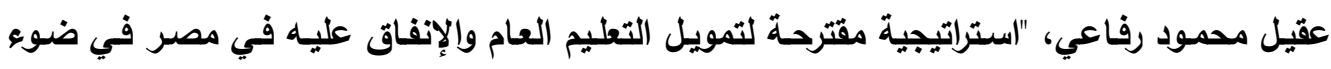

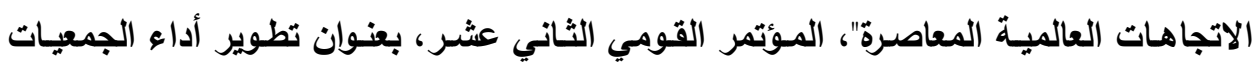

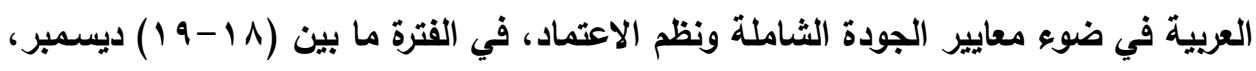

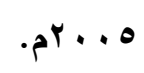

كليـر فهيم، رعايـة الأبنـاء ذوي الاحتياجـات الخاصـة، القـاهرة: الهيئة المصـرية العامـة للكتـاب،

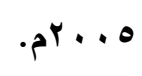

نجدة إبراهيم علي، نظم التعليم في التريبة الخاصة، القاهرة: الثمس للطباعة، ... بام.

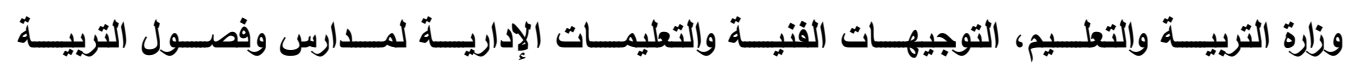

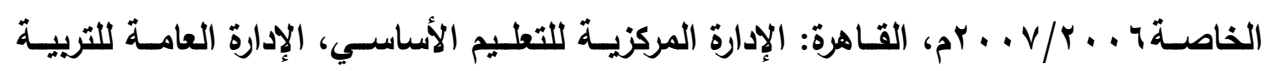

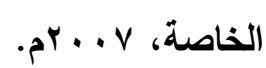
وزارة التربية والتطليم، الخطة الاستراتيجية القومية لإصلاح التطليم قبل الجامعي في مصر (^... بم- 
وزارة التربية والتعليم، القزار الوزاري رقم (14 1)، في شان توزيع الاختصاصات والمسئوليات بالإدارة العامة للتربية الخاصة، القاهرة، ه19 91 ام.

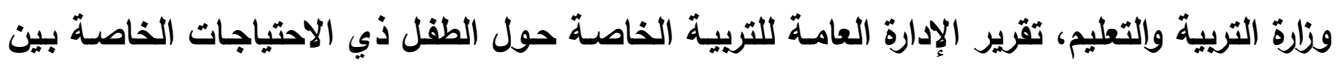

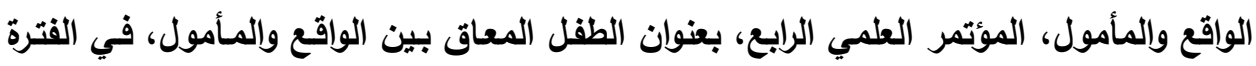

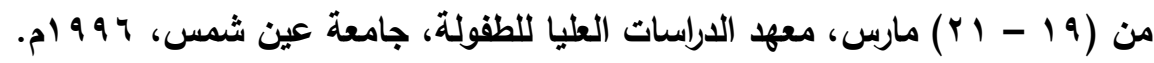

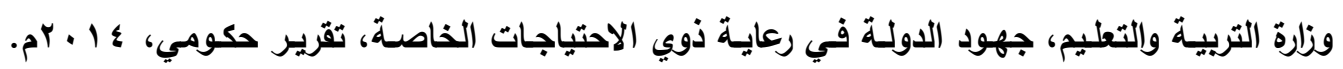

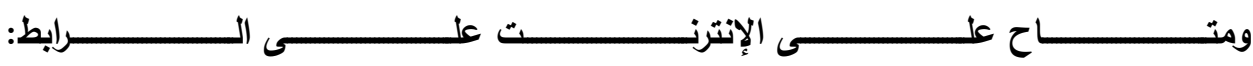

http://www.masrawy.com/News/News_Egypt/details/20

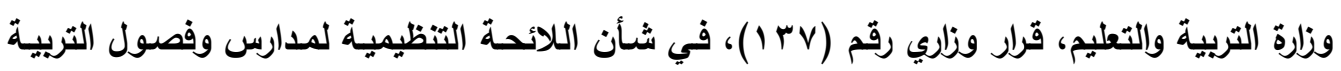

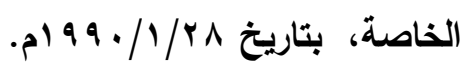

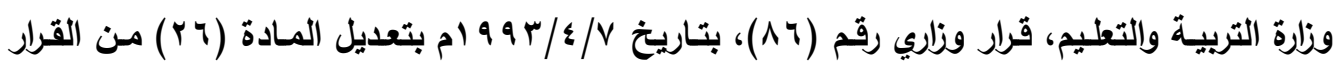

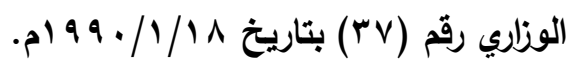

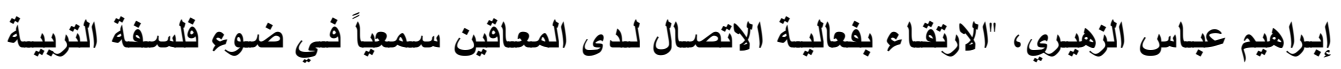

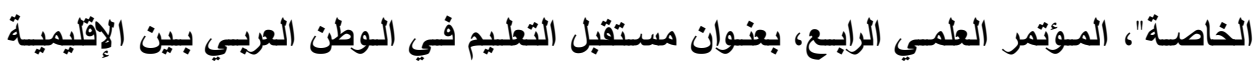

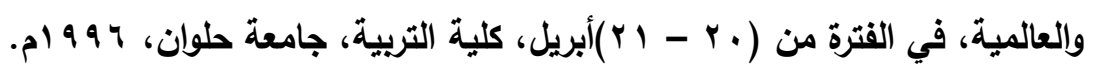

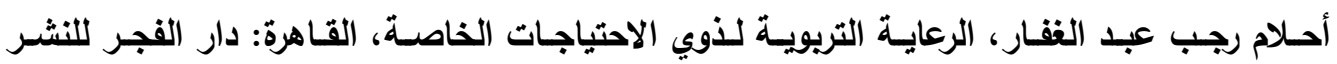

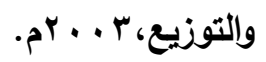

Florence, J. General Education Teacher Recommendations for the Inclusive Education of Student with Special Needs, USA, 2005.

Jean, G. Special Education, Available on internet at: https://ar.wikipedia.org/wiki/jean.

Joan, d. managing special needs in the primary school, Taylor and Francis, London, 2002.

Weintraub, F. The Evolution of ID Policy and Future Challenges, Learning Disability Quarterly, USA, vol28, 2005. 